\title{
Centrin 2 Is Required for Mouse Olfactory Ciliary Trafficking and Development of Ependymal Cilia Planar Polarity
}

\author{
Guoxin Ying, ${ }^{1}$ Prachee Avasthi, ${ }^{1}$ Mavis Irwin, ${ }^{3}$ Cecilia D. Gerstner, ${ }^{1}$ Jeanne M. Frederick, ${ }^{1}$ Mary T. Lucero, ${ }^{3}$ \\ and Wolfgang Baehr ${ }^{1,2,4}$ \\ Departments of ${ }^{1}$ Ophthalmology, and ${ }^{2}$ Neurobiology and Anatomy, University of Utah Health Science Center, Salt Lake City, Utah 84132, and Departments \\ of ${ }^{3}$ Physiology and ${ }^{4}$ Biology, University of Utah, Salt Lake City, Utah 84112
}

Centrins are ancient calmodulin-related $\mathrm{Ca}^{2+}$-binding proteins associated with basal bodies. In lower eukaryotes, Centrin2 (CETN2) is required for basal body replication and positioning, although its function in mammals is undefined. We generated a germline CETN2 knock-out (KO) mouse presenting with syndromic ciliopathy including dysosmia and hydrocephalus. Absence of CETN2 leads to olfactory cilia loss, impaired ciliary trafficking of olfactory signaling proteins, adenylate cyclase III (ACIII), and cyclic nucleotide-gated (CNG) channel, as well as disrupted basal body apical migration in postnatal olfactory sensory neurons (OSNs). In mutant OSNs, cilia baseanchoring of intraflagellar transport components IFT88, the kinesin-II subunit KIF3A, and cytoplasmic dynein 2 appeared compromised. Although the densities of mutant ependymal and respiratory cilia were largely normal, the planar polarity of mutant ependymal cilia was disrupted, resulting in uncoordinated flow of CSF. Transgenic expression of GFP-CETN2 rescued the Cetn2-deficiency phenotype. These results indicate that mammalian basal body replication and ciliogenesis occur independently of CETN2; however, mouse CETN2 regulates protein trafficking of olfactory cilia and participates in specifying planar polarity of ependymal cilia.

Key words: centrin 2 knock-out; ciliary maintenance; ciliary trafficking; ependymal cilia; olfactory cilia; planar cell polarity

\section{Introduction}

Cilia are organelles important for cellular sensation, motility, and signaling. Olfactory cilia emanate from the dendritic knob of the olfactory sensory neuron (OSN) and harbor signaling proteins needed to convert odor stimuli into electrical signals. Photoreceptor outer segments are specialized light-sensing cilia housing phototransduction proteins. Motile cilia of multiciliated cells, e.g., ependymal cilia lining the brain ventricle wall, airway respiratory cilia, and fallopian tube cilia, propel liquid or cell movement along luminal surfaces. Cilia dysfunction causes a wide range of human diseases collectively called ciliopathies. Disrup-

\footnotetext{
Received Jan. 7, 2014; revised March 27, 2014; accepted March 29, 2014.

Author contributions: G.Y.,P.A., and W.B. designed research;G.Y., P.A., M.I., C.D.G., J.M.F., and M.T.L. performed research; G.Y., M.I., and M.T.L. analyzed data; G.Y., J.M.F., and W.B. wrote the paper.

This work was supported by NIH Grants EY08123, EY019298 (W.B.); EY014800-039003 (NEl core grant); DC 002994 (M.L.); DC011686, Blackman Trust Fund and University of Utah Graduate Research Fellowship (M.I.); and unrestricted grants to the University of Utah Department of Ophthalmology from Research to Prevent Blindness (New York). W.B. is the recipient of a Research to Prevent Blindness Senior Investigator Award. We thank R. Vallee (Columbia University, NYC) for antibodies directed against DYNC2H1 and DTYNC1H1, J. Besharse (Medical College of Wisconsin, Milwaukee) for antibody recognizing IFT88, U. Wolfrum (Johannes Gutenberg Universität, Germany) for antibody recognizing CETN2, H. Breer (Universität Hohenheim, Germany) for antibody recognizing 0R256-17, and R. Molday (University of British Columbia, Canada) for antibodies directed against rhodopsin, ROM1 and peripherin 2. The authors declare no competing financial interests.

Correspondence should be addressed to either Dr Guoxin Ying or Dr Wolfgang Baehr, Moran Eye Center, University of Utah Health Science Center, 65 Mario Capecchi Drive, Salt Lake City, UT 84132, E-mail: g.ying@utah.edu or wbaehr@hsc.utah.edu.

P. Avasthi's present address: Departments of Biochemistry and Biophysics, University of California, San Francisco, CA 94158.

M. T. Lucero's present address: Department of Neuroscience and Physiology, American University of the Caribbean, 1 University Drive, Cupecoy, St Maarten Netherlands Antilles.

DOI:10.1523/JNEUROSCI.0067-14.2014

Copyright $\odot 2014$ the authors $\quad 0270-6474 / 14 / 346377-12 \$ 15.00 / 0$
}

tion of olfactory cilia causes anosmia (inability to perceive odors) or dysosmia (reduced sensitivity to odors; Kulaga et al., 2004; McEwen et al., 2007; Tadenev et al., 2011; McIntyre et al., 2012), whereas ependymal cilia dysfunction leads to impaired CSF flow and hydrocephalus (Lechtreck et al., 2008; Tissir et al., 2010; Wilson et al., 2010).

Intraflagellar transport (IFT) is a highly conserved mechanism that regulates the trafficking of axoneme building blocks, tubulin, sensory receptors, and other transmembrane proteins (Kozminski et al., 1995; Marshall et al., 2005; Qin et al., 2005; Huang et al., 2007; Mukhopadhyay et al., 2010; Ocbina et al., 2011). Motile cilia additionally require planar cell polarity (PCP) for proper function, i.e., the cilia must be oriented uniformly such that their coordinated beating can generate a directional fluid flow. The basal body at the ciliary base appears to be critical for both entry of the signaling protein and establishment of planar polarity (Marshall, 2008b). The basal body distal appendage, or "transitional fiber", together with the ciliary transition zone, may compromise a "gate" for ciliary entry (Williams et al., 2011; Wei et al., 2013; Ye et al., 2014), whereas the subdistal appendage, or "basal foot", determines polarity, with its absence in mice causing uncoordinated ciliary beating (Kunimoto et al., 2012).

Centrins, $\sim 20 \mathrm{kDa} \mathrm{Ca}{ }^{2+}$-binding proteins, are core basal body/centriole proteins that are included among the several hundred eukaryote "signature proteins" found in all eukaryotic cells but not in archaea or bacteria (Hartman and Fedorov, 2002). Centrins are required for basal body genesis and positioning in lower eukaryotes, such as algae, ciliates, and yeast (spindle pole body; Salisbury, 2007). Mammals have four centrin genes: Chlamydomonas centrin ( $v f l 2$ )-related CETN1, 2, and 4, and yeast 


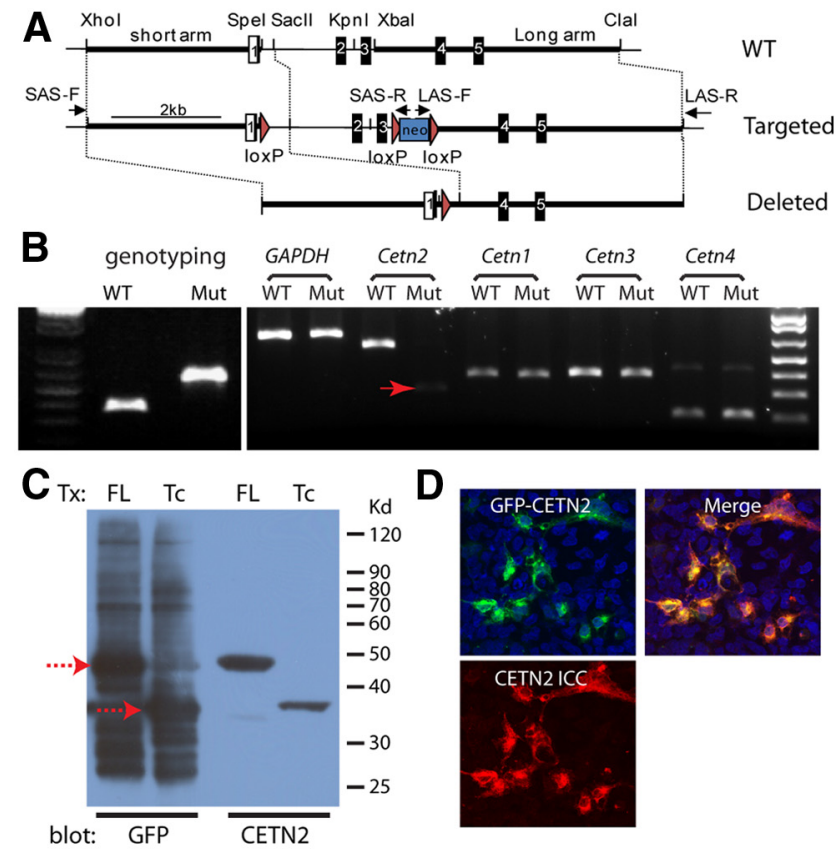

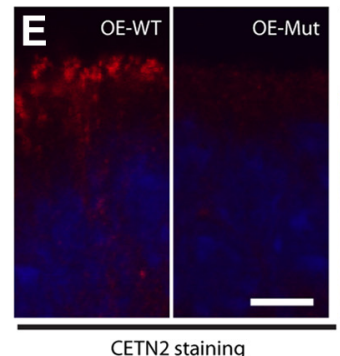
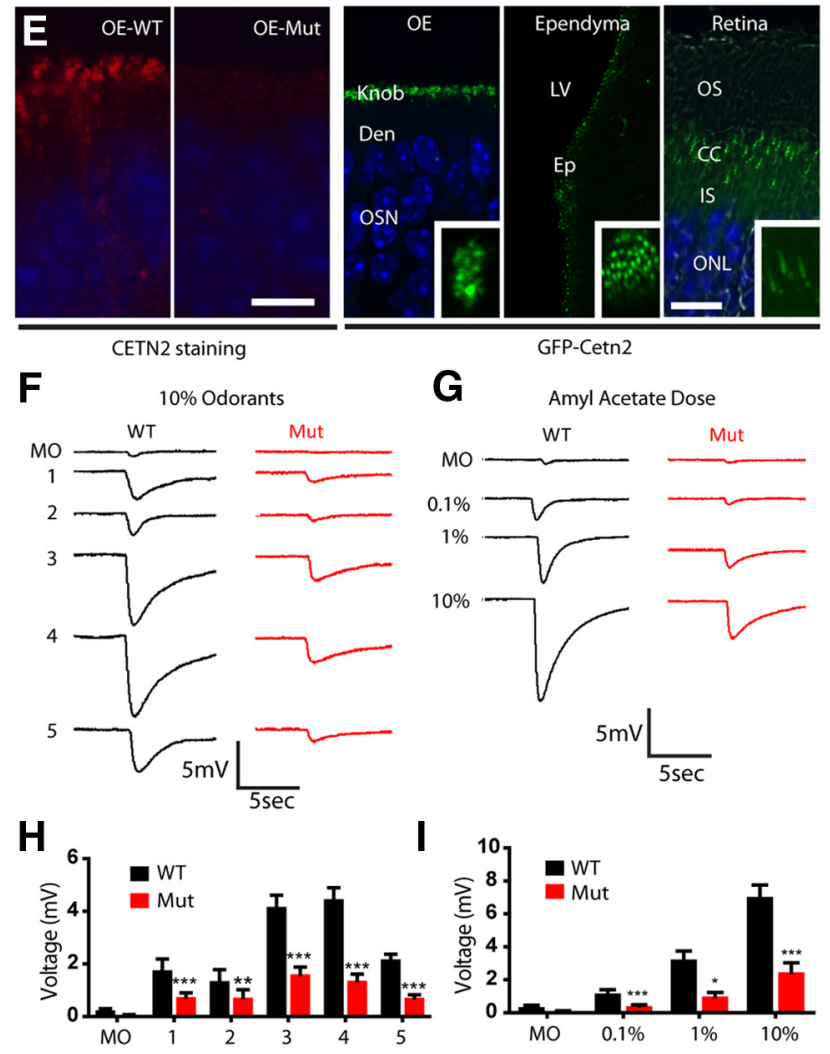

GFP-Cetn2
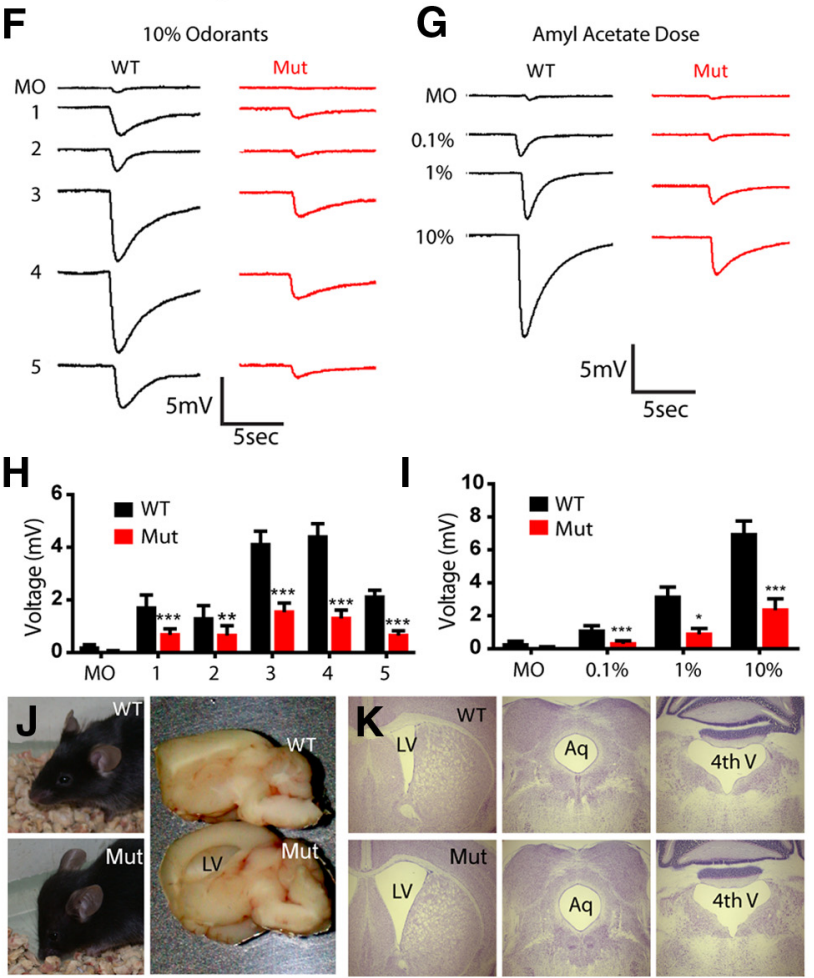

Figure 1. Generation of Cetn $2^{\Delta \mathrm{Ex} 2,3}$ mice manifesting the phenotype of dysosmia and hydrocephalus. $\boldsymbol{A}$, Schematic of gene targeting strategy. $\boldsymbol{B}, \mathrm{PCR}$ genotyping of Cetn $2^{\Delta \mathrm{Ex} 2,3}$ mouse (357 bp for WT, 593 bp for mutant) and RT-PCR examination of Cetn 1-4 mRNA expression in OE. GAPDH was used as an internal control. Red arrow marks the faint band of truncated centrin (CDC31)-related CETN3 (Friedberg, 2006; Bornens and Azimzadeh, 2007) of largely undefined function. Germ line KO of Cetn 1 in mouse leads to male infertility due to a centriole rearrangement defect causing failure of spermiogenesis (Avasthi et al., 2013). The physiological roles of mammalian CETN2-4 are unknown.

Here, we show that Cetn2 KO mice develop a syndromic ciliopathy comprised of dysosmia and hydrocephalus. The dysosmia phenotype is caused by impaired ciliary transport of olfactory signaling proteins, olfactory cilia loss, and defective postnatal basal body positioning accompanied by compromised basal body anchoring of IFT components. The hydrocephalus is caused by impaired CSF flow attributed to disrupted ependymal cilia PCP without cilia loss. These phenotypes can be rescued by transgenic expression of a GFP-CETN2 fusion protein governed by a universal promoter.

\section{Materials and Methods}

Generation of Cetn2 KO mouse. BAC clone RP23-307G22 (205.2KB) containing the Cetn2 gene was purchased from Children's Hospital Oakland Research Institute. An $8.5 \mathrm{~Kb}$ XhoI/ClaI fragment was subcloned into plasmid vector $\mathrm{pBS}-\mathrm{SK}+$. We inserted a LoxP site into the first intron by NheI cloning, and a neomycin selection cassette flanked by two LoxP sites into intron 3 by XbaI cloning. The target vector sequence was confirmed by complete sequencing of the insertion. Plasmid electroporation of 129SV-derived embryonic stem cells, blastocyst injection, and generation of agouti and F1 heterozygous mice were performed by Ingenious Targeting). PCR was used to screen correctly recombined ES cell clones and F1 mice. PCR primers included: (1) random integration: Cetn2VecScr.F: TGGCGTAATCATGGTCATAGC and Cetn2VecScr.R: CACGACAGGTTTCCCGAC; (2) 5' primer recombination arm: Cetn2SAS.F: AGGAACAGAGTGTGAAGTTAGAC and Cetn2SAS.R: AGACAGAATAAAACGCACGGG; (3) 5' LoxP: SpeLinkerChk.F: AAACCAATGGGAAGCGGGC and SpeLinker Chk.R: CTGAAGGT GACTTGGGCGAG; and (4) 3' recombination arm: Cetn2LAS.F: GAAGTAGCCGTTATTAGTGG and Cetn2LAS.R: TCTCTGGTACAG TCATGC. Mice with the targeted allele are designated Cetn2 3LoxP, and were crossed with an EIIa-Cre driver to generate progeny with the exons 2 - and 3-deleted allele $\left(\operatorname{Cetn} 2^{\Delta \mathrm{Ex} 2,3}\right)$. EIIa-Cre-driven recombination also removed a neomycin cassette, thus eliminated potential interfering effect of neomycin on nearby gene expression. PCR genotyping primers were as follows: first LOXP F: GAGTACGCCGTTGCCTTAAC; first LoxP R: GTTTGACTGAGGCGGAAGTC; and third LoxP R: GGC CCTGAGTCCTTGTAATG, which amplify fragments of 357 bp (WT) and $593 \mathrm{bp}$ (mutant).

Mice. C57BL/6 mice were obtained from Charles River Laboratories. EIIa-Cre and GFP-Cetn2 transgenic mice (Higginbotham et al., 2004) were obtained from

\footnotetext{
Cetn $^{\triangle \text { Ex2,3 }}$ mRNA. C, Immunoblot detection of full-length (FL) GFP-CETN2 and truncated (TC) GFP-CETN2 (red dashed arrows, 48 and 37 kDa, respectively) overexpressed in HEK-293 cells. Blots were probed with GFP antibody (left two lanes) and or CETN2 antibody (right two lanes). D, Immunofluorescence of truncated GFP-CETN2 in transfected HEK-293 cells. Endogenous GFP signal (green), with nuclear DAPI signal (blue) are shown; (ETN2 antibody labeling, red (left, bottom); and merged view (right). $\boldsymbol{E}$, (ETN2 immunofluorescence of WT and mutant OE (left two panels), and expression of transgenic GFP-CETN2 in OE, ependyma, and retina photoreceptors (right three panels with insets). Den, Dendrite; LV, lateral ventricle; EP, ependyma; OS, outer segment; $C$ C, connecting cilium; IS, inner segment; $0 \mathrm{NL}$, outer nuclear layer. Scale bar, 5 $\mu \mathrm{m} . \boldsymbol{F}, \boldsymbol{G}$, Representative EOG responses to various odors $(\boldsymbol{F})$ and dose-dependent test of amy acetate (G). M0, Mineral oil; 1, citral; 2, S-butanol; 3, acetophenone; 4, cineole; 5, R-carvone. $\boldsymbol{H}$, $I$, Quantification of EOG results showing reduced voltage responses to tested odors $(\boldsymbol{H})$ and at every amyl acetate concentration $(I)$. Error bars indicate mean $\pm \mathrm{SD}(n=7 \mathrm{WT}, n=9$ mutants, two-way ANOVA, $\left.{ }^{*} p<0.05,{ }^{* *} p<0.01,{ }^{* * *} p<0.001\right)$.J, Severe hydrocephalus of P30 Cetn2 mutant mouse, showing dome-shaped head and dilated lateral ventricle of brain. $\boldsymbol{K}$, Mild hydrocephalus of Cetn2 mutant mouse, showing dilation of lateral ventricle (LV) but not of aque$\operatorname{duct}(\mathrm{Aq})$ or fourth ventricle (4th V).
} 


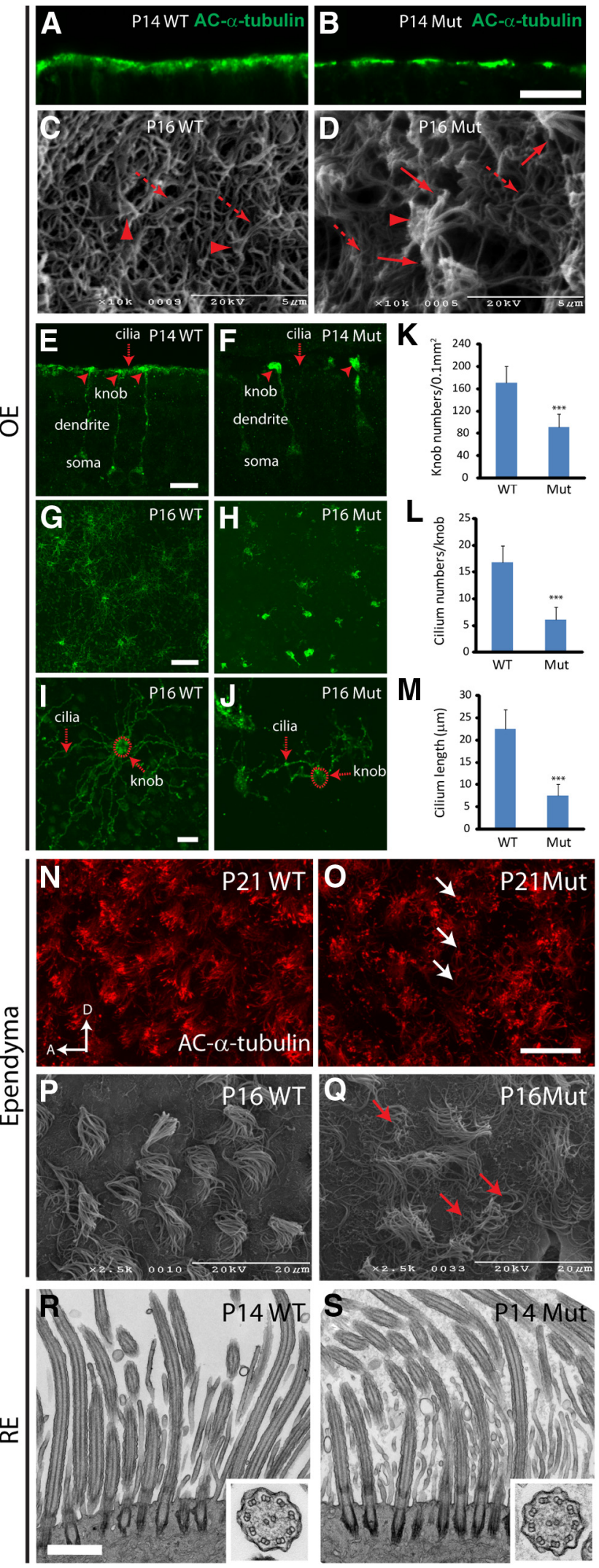

Figure 2. Loss of olfactory $(\boldsymbol{A}-\boldsymbol{M})$, but not ependymal $(\boldsymbol{N}-\mathbf{Q})$ and respiratory $(\boldsymbol{R}, \boldsymbol{S})$, cilia in Cetn2 mutant mice. $A, B$, Decrease and interruption of cilia marker, $A c-\alpha$-tubulin, staining in P14 mutant OE. C, D, SEM images of P16 WT and mutant OE. Individual knobs (red arrowheads), normal cilia (dashed arrows), and abnormal cilia (right, solid arrows) of the mutant are identified. $\boldsymbol{E}-\boldsymbol{J}$, 0R256-17 labeling of cilia in P14 OE section $(\boldsymbol{E}, \boldsymbol{F})$ and P16 whole-mount $(\mathbf{G}-\boldsymbol{J})$ preparations, showing greatly reduced density and abnormal cilium morphology in mutants.
The Jackson Laboratory. All experiments were approved by the University of Utah Institutional Animal Care and Use Committee.

$R T$-PCR. Olfactory epithelia (OE) from male WT and Cetn2 mutant mice were dissected and total RNA was extracted using TRIzol reagent (Invitrogen). Reverse transcription was performed using SuperScript II reverse transcriptase (with random primers). Centrin isoform primers and cycle numbers are as follows: Cetn1 (32 cycles, $390 \mathrm{bp}$ ), forward: GTCCAC CTTCAGGAAGTCAAAC and reverse: TCATTGGCCACACGCTTGAG; Cetn 2 (27 cycles; $601 \mathrm{bp}$ for WT, $313 \mathrm{bp}$ for mutant) forward: GAGTACGCCGTTGCCTTAAC and reverse: GTCACATGTGCTTGCAGTAG; Cetn3 (24 cycles, 403 bp), forward: GCTCTGAGAGGTGAGCTTGTAG and reverse: CCTCATCGCTCATGTTCTCAC; Cetn4 (26 cycles, $216 \mathrm{bp}$ ), forward: CCAGCCAGCGCATAACTTTAG and reverse: CCTTGTCGATTTCAGCGATCAG. GAPDH served as an internal control (18 cycles, 703 bp), forward: GCCATCAACGACCCCTTCAT and reverse: ATGCCTGCTTCACCACCTTC. RT-PCR was repeated once.

Centrin expression. Full-length and truncated mouse Cetn 2 were amplified by RT-PCR using Phusion enzyme (Finnzymes) and cloned into pEGFP-C1 using EcoR I/BamH I cloning sites. The primers are as follows: Cetn2-full-length, forward: GCCGAATTCCGCCTCTAATTT TAAGAAGACAAC and reverse: CTGGGATCCTGATCTTAATAGA GGCTGGTC; Cetn2-truncated, forward: GCCGAATTCCTCTGA GAAAGACACTAAAGAAG and same reverse primer. HEK-293 cells (ATCC) were cultured in MEM supplemented with 10\% FBS and $0.5 \times$ antibiotics (all from Invitrogen). Cells were transfected with Lipofectamine 2000 (Invitrogen) following manufacturer's protocol. Transfected cells were lysed for Western blot analysis or fixed for immunofluorescence detection.

$E O G$ and ERG. Electro-olfactograms (EOGs) were performed on male Cetn2 mutants $(n=9)$ and WT littermates $(n=7)$ at $4-6$ weeks of age. Dose-response curves were generated for amyl acetate and 2 -heptanone ( $0,0.1,1$, and $10 \%$ in mineral oil as vehicle). Additional odorants were tested at $10 \%$ dilution and included S-butanol, acetophenone, cineole, R-carvone, and citral. Mineral oil was used as baseline control. Mice were killed by cervical dislocation, the heads hemisectioned and olfactory turbinates were exposed. Mounted onto a stereomicroscope stage, the olfactory turbinates were maintained under humidified, filtered air stream at $35^{\circ} \mathrm{C}$. Odorants $(10 \mu \mathrm{l}$ diluted stock solutions) were applied to a sterile pipette filter and introduced into the humidified air stream using a picospritzer. Recordings were made at three locations (turbinates II, II' , and III) with a glass electrode filled with Ringer's solution ( $140 \mathrm{~mm} \mathrm{NaCl}, 5 \mathrm{~mm} \mathrm{KCl}, 1 \mathrm{~mm} \mathrm{MgCl}, 2 \mathrm{~mm} \mathrm{CaCl}_{2}, 10$ mM HEPES, $10 \mathrm{~mm}$ glucose). The preparation was grounded by a silver chloride wire inserted into a $3 \mathrm{M} \mathrm{KCl}$ agar bridge placed near the skull bone. EOG responses were acquired at a sampling rate of $400 \mathrm{~Hz}$ and filtered at $200 \mathrm{~Hz}$ using an Axoclamp 200B and Digidata 1340 interface running Axoscope 7.2 software. Averaged peak amplitudes were used for data analysis using two-way ANOVA with Bonferroni post-tests.

ERG was performed on 1-month-old male Cetn2 mutant and WT littermates ( $n=3$ each) using an UTAS E-3000 universal electrophysiological system (LKC Technologies) as described previously (Jiang et al., 2011). Peak amplitudes for both a- and b-waves were used for analysis using one-way ANOVA test.

Immunofluorescence and confocal microscopy. Except for CETN2 immunostaining, specimens (most were from male animals) were fixed by immersion in ice-cold $4 \%$ paraformaldehyde for 3-8 h (olfactory tissue) or $2 \mathrm{~h}$ (retina). Postnatal day (P) 10 to adult olfactory tissues were decal-

Labeled cilia (arrows) and dendritic knobs (arrowheads in section, dashed circles in wholemount) are indicated. $\boldsymbol{K}-\boldsymbol{M}, \mathrm{Knob}$ density $(\boldsymbol{K})$, cilia density $(\boldsymbol{L})$ and average ciliary length $(\boldsymbol{M})$ are decreased significantly in mutants. Data shown as mean $\pm S D(n \geq 450 S \mathrm{Ns}$ from 3 animals for each group; one-way ANOVA, $\left.{ }^{* * *} p<0.001\right) . \mathbf{N}, \mathbf{0}, \mathrm{Ac}-\alpha$-tubulin immunolabeling of $\mathrm{P} 21$ brain lateral ventricle whole-mount reveals that mutant ependymal cilium density is comparable with WT, but the orientation of cilia is disrupted with disorganized tufts ( $\mathbf{O}$, arrows). D, Dorsal; $A$, anterior. $\boldsymbol{P}, \mathbf{Q}$, SEM of $\mathbf{P} 16$ ependymal cilia showing disorganized ciliary orientation in mutants ( $\boldsymbol{Q}$, arrows). $\boldsymbol{R}, \mathbf{S}$, TEM of $P 14$ respiratory cilia in WT and mutant with cilium cross sections (insets). Scale bars: $\boldsymbol{A}, \boldsymbol{B}, \boldsymbol{E}-\boldsymbol{H}, \boldsymbol{N}, \mathbf{O}, 10 \mu \mathrm{m} ; \boldsymbol{C}, \boldsymbol{D}, \boldsymbol{I}, \boldsymbol{J}, 5 \mu \mathrm{m} ; \boldsymbol{P}, \mathbf{Q}, 20 \mu \mathrm{m} ; \boldsymbol{R}, \mathbf{S}, 1 \mu \mathrm{m}$. 

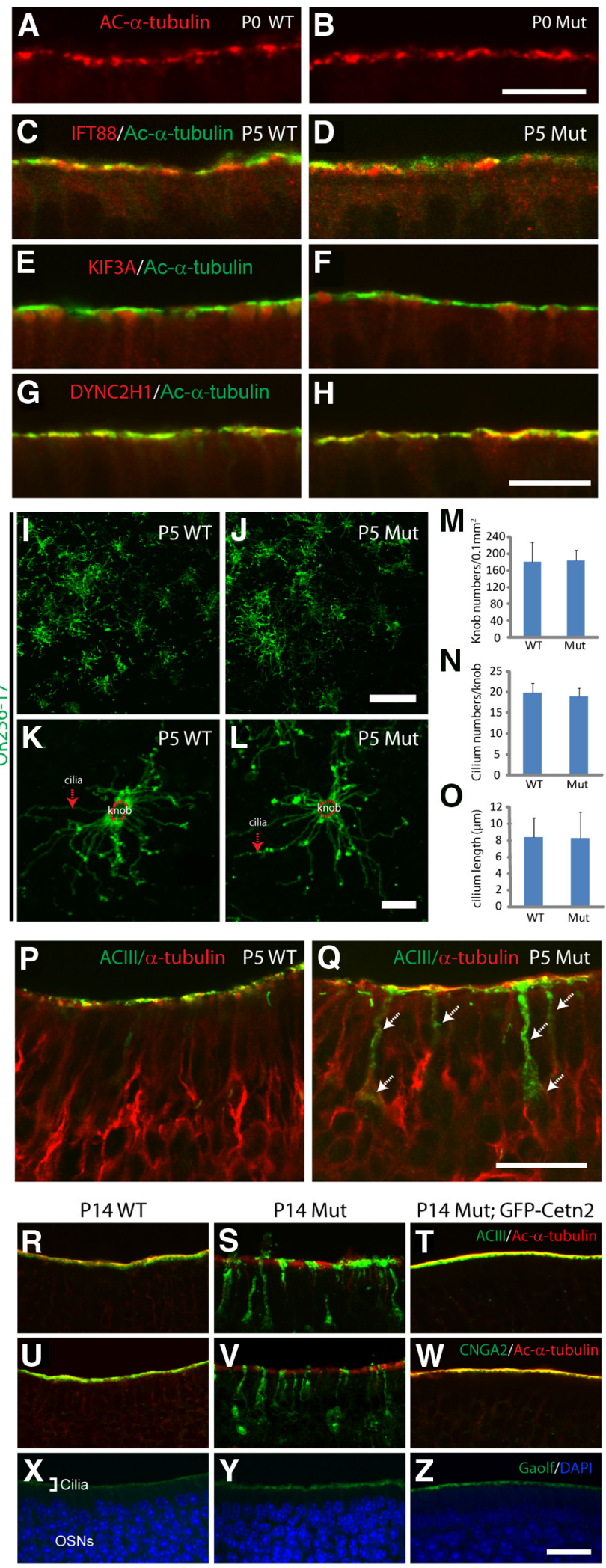

P14 Mut; GFP-Cetn2

Figure 3. Mislocalization of ACIII and CNGA2 occurs before ciliary loss in Cetn2 mutant. $A, B$, Ac- $\alpha$-tubulin immunolabeling of PO WT and mutant 0 E. $C-H$, Colabeling of IFT88 (C, D), KIF3A $(\boldsymbol{E}, \boldsymbol{F})$, and DYNC2H1 $(\boldsymbol{G}, \boldsymbol{H}$; all red) with Ac- $\alpha$-tubulin (green) in P5 WT and mutant $0 \mathrm{E}$, showing comparable patterns. I-L, OR256-17 staining of P5 WT and mutant whole-mount 0 E at low- $(I$, $\boldsymbol{J})$ and high-magnification $(\boldsymbol{K}, \boldsymbol{L}) . \boldsymbol{M}-\mathbf{0}$, No statistical difference of knob density $(\boldsymbol{M})$, cilia per $\operatorname{knob}(\boldsymbol{M})$, or average ciliarylength $(\boldsymbol{O})$ was observed. Data are mean $\pm \mathrm{SD}$ (one-way ANOVA, $p>0.8$, $n \geq 450$ OSNs from 3 animals per group). $P, Q$, Colabeling of $P 5$ turbinate I OE. ACIII (green) colocalizes with $\alpha$-tubulin (red) at the cilium layer of WT $(\boldsymbol{P})$, but is partially mislocalized to the cified in 10\% EDTA, pH 7.3, before cryoprotection in 30\% sucrose; embryonic and neonatal olfactory tissue/retinas were directly transferred to sucrose after fixation. Specimens were embedded in Optimal Cutting Temperature (OCT) compound and frozen. Sections ( $12 \mu \mathrm{m}$ thick) were cut using a micron cryostat and mounted on charged Superfrost Plus slides (Fisher). Sections were washed in $0.1 \mathrm{~m}$ PBS, blocked using $10 \%$ normal goat serum or $2 \%$ BSA with $0.1-0.3 \%$ Triton X-100 in PBS, and incubated with primary antibodies at $4^{\circ} \mathrm{C}$ overnight. After PBS washes, signals were detected using Cy3-conjugated or AlexaFluor 488-conjuated goat anti-rabbit/mouse, or donkey anti-goat/rabbit secondary antibodies, and counterstained with DAPI. For CETN2 staining, nasal turbinates were isolated and immediately embedded in OCT. The cut sections were fixed in methanol for $20 \mathrm{~min}$ at $-20^{\circ} \mathrm{C}$ before proceeding to immunostaining. Primary antibodies were as follows: rabbit anti-CETN2 (1:200 dilution, Santa Cruz Biotechnology), adenylate cyclase III (ACIII; 1:1000, Santa Cruz Biotechnology), cyclic nucleotide-gated channel (CNGA2; 1:300, Alomone Labs), G $\alpha_{\text {olf }}$ (1:200, Santa Cruz Biotechnology), KIF3A (1:500 Sigma-Aldrich), and rod cGMP phosphodiesterase (PDE6), ML- and S-opsin, rod transducin- $\alpha$, rod arrestin (all 1:1000, Cell Signaling Technology), DYNC2H1 (cytoplasmic dynein 2 heavy chain 1; 1:500; Dr Vallee, Columbia University, New York, NY), OR257-17 (1:500; Dr Breer, University of Hohenheim, Germany), mouse anti-acetylated $\alpha$-tubulin (1:1000, Sigma-Aldrich), $\gamma$-tubulin (1: 500, Sigma-Aldrich), $\alpha$-tubulin (1:1000, Sigma-Aldrich), CNGA1/A3 (1: 2000, NeuroMab), guanylate cyclase 1 (GC1) (1:2000, IS4) and rhodopsin (1D4), ROM1, Peripherin 2 (1:1000, Dr Molday, University of British Columbia); goat anti-CETN2 (1:400; Dr Wolfrum, Johannes Gutenberg University, Mainz, Germany), and IFT88 (1:200; Dr Besharse, Medical College of Wisconsin).

For whole-mount OR256-17 immunolabeling, essentially the same procedure was used with antibody incubation occurring overnight. Ependyma whole-mount AC- $\alpha$-tubulin immunostaining was performed as described previously (Mirzadeh et al., 2010). Cultured cells were fixed in $4 \%$ PFA for $10 \mathrm{~min}$ at room temperature and permeabilized in $0.1 \%$ Triton X-100 for 5 min followed by immunolabeling. Images were acquired using an Olympus Fluoview 1000 confocal microscope and adjusted for brightness/contrast using Adobe Photoshop CS3.

Electron microscopy. For scanning electron microscopy, P16 male Cetn 2 mutant and WT control mice were killed. The heads were hemisectioned; turbinates were exposed ( $n=3$ each) and fixed overnight in $2.5 \%$ glutaraldehyde, $1 \%$ paraformaldehyde in $0.1 \mathrm{~m}$ sodium cacodylate buffer, $\mathrm{pH} 7.4$, at $4^{\circ} \mathrm{C}$. After several washes, samples were dehydrated in an ascending ethanol solution series and dried in hexamethyldisilazane. Dried samples were coated with gold particles and examined using the University of Utah EM core facility scanning microscope (Hitachi S-2460N) at $20 \mathrm{KV}$.

For transmission electron microscopy, P14 male Cetn2 mutant and WT control specimens ( $n=3$ each) were fixed $2 \mathrm{~h}$ in the (above) fixative at $4^{\circ} \mathrm{C}$, washed, and postfixed $2 \mathrm{~h}$ in $2 \%$ osmium tetroxide in $0.1 \mathrm{~m}$ sodium cacodylate buffer, $\mathrm{pH} 7.4$, at $4^{\circ} \mathrm{C}$. Washed specimens were dehydrated through an ascending series of ethanol, dried in propylene oxide and infiltrated overnight with Epon resin mix/propylene oxide (1:1) mixture, followed by $100 \%$ Epon resin for $2 \mathrm{~d}$. Specimens were embedded in plastic, and the plastic was cured by incubation in a $60^{\circ} \mathrm{C}$ oven for $2 \mathrm{~d}$. Blocks were trimmed, and $1-\mu \mathrm{m}$-thick sections were cut and examined until desired area was reached. Ultrathin sections were cut, stained with uranyl acetate and lead citrate, and examined with an electron transmission microscope (FEI Tecnai 12) at the University of Utah EM core facility.

dendrite and cell body (arrows) in mutant (Q). Mutant olfactory cilia appear intact at this stage. $\boldsymbol{R}-\boldsymbol{T}$, Double-immunofluorescence of ACIII (green) and Ac- $\alpha$-tubulin (red) in P14 WT ( $\boldsymbol{R}$ ), Cetn2 mutant (S), and Cetn2 Mut;GFP-Cetn2 ( $\boldsymbol{T}$ ) OE. $\mathbf{0}-\mathbf{Q}$, Double-staining of CNGA2 (green) and Ac- $\alpha$-tubulin (red) in P14 WT (U), Cetn2 mutants ( $\boldsymbol{V}$, and Cetn2 Mut;GFP-CETN2 (W) OE. $\boldsymbol{X}$ - $\boldsymbol{Z}$, Immunofluorescence of $G \alpha$ olf in $0 \mathrm{E}$. G $\alpha$ olf localizes in cilia layer of P14 WT $(\boldsymbol{X})$, mutant $(\boldsymbol{\eta})$, and Cetn2 Mut;GFP-Cetn2 (Z) OE. Please note the endogenous GFP-CETN2 signal was quenched in $T$ $W, Z$ by boiling in $10 \mathrm{~mm}$ sodium citrate, $\mathrm{pH} 6.0$, for $20 \mathrm{~min}$ before staining. Scale bars: $A, B, I, J$, $P, \mathbf{Q}, 10 \mu \mathrm{m} ; \boldsymbol{K}, \mathbf{L}, 5 \mu \mathrm{m} ; \boldsymbol{R}-\mathbf{Z}, 30 \mu \mathrm{m}$. 

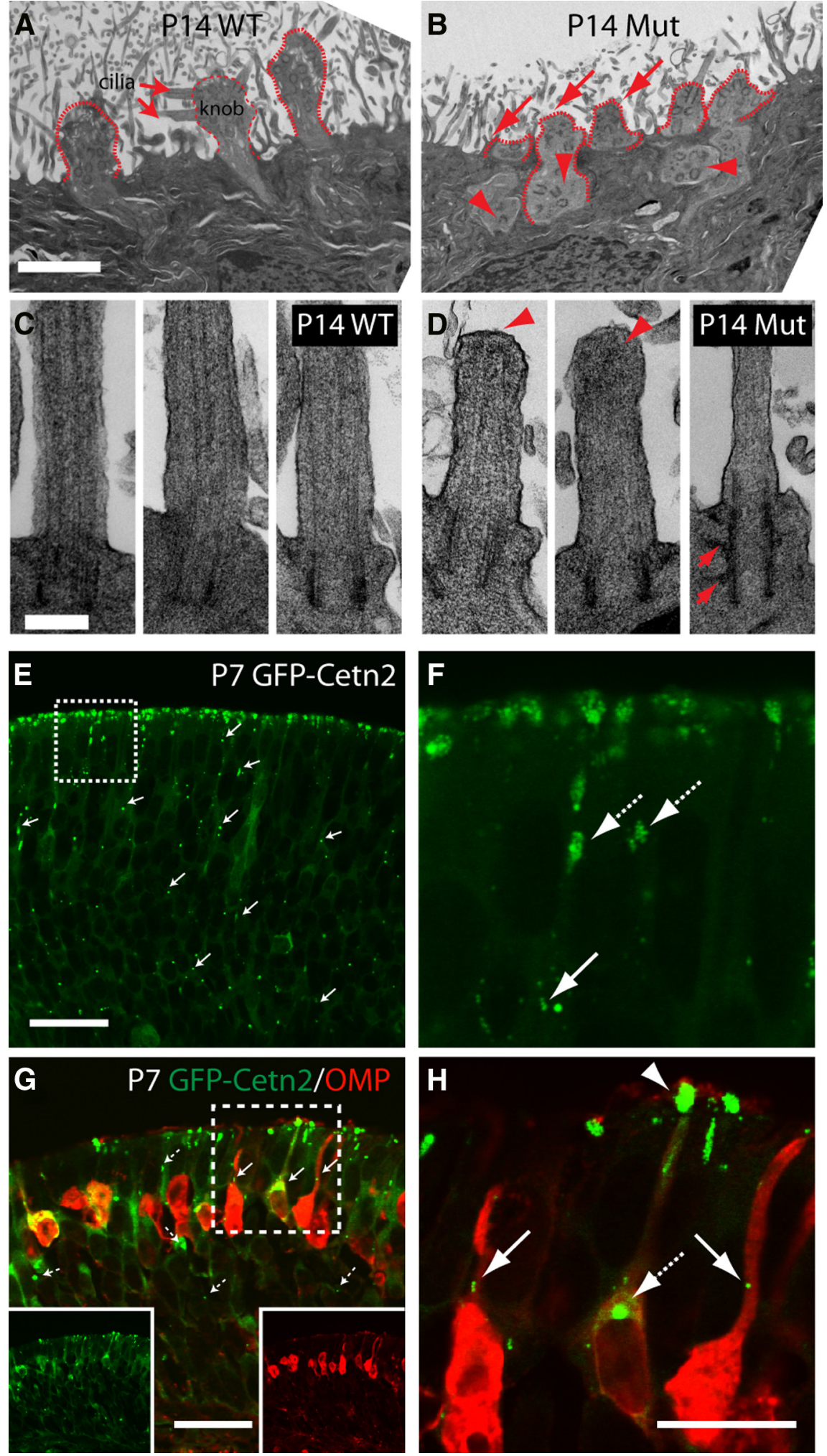

Figure 4. Basal-body apical migration defects in postnatal Cetn2 mutant OSNs. A, B, P14 WT and mutant OE ultrastructure, turbinate Il. Olfactory cilia (arrows) are present in $\boldsymbol{A}$ and absent in $\boldsymbol{B}$. Dendritic knobs (dashed lines) and mislocalized basal bodies (arrowheads) beneath the mutant epithelial surface are shown. $\boldsymbol{C}, \boldsymbol{D}$, Magnified TEM views of WT and mutant olfactory cilia. Swollen tips of remaining mutant cilia ( $\boldsymbol{D}$, arrowheads) and elongated basal bodies with abnormal electron-dense decoration (arrows) are indicated. $\boldsymbol{E}, \boldsymbol{F}$, GFP-CETN2-labeled basal body distribution ( $\boldsymbol{E}$, white arrows) in P7 GFP-CETN2 transgenic mouse 0 E. Boxed area in $\boldsymbol{E}$ was enlarged in $\boldsymbol{F}$. Dashed arrows mark clustered basal bodies that might undergo apical migration within dendrites. Arrow labels basal bodies within OSN cell bodies. G, OMP (red) immunostaining in P7 GFP-CETN2 transgenic mouse 0 E. A fraction of GFP-CETN2 signal located in OMP-positive OSNs (arrows) with majority located in OMP-negative cells. $\boldsymbol{H}$, Enlargement of boxed area in G. Arrows mark two GFP-CETN2 spots in dendrites of OMP-positive neurons. Dashed arrow points to a large clump
Co-IP and Western blot. Olfactory epithelia from transgenic GFP-Cetn2 and WT mice (both male and females) were dissected while submerged in ice-cold PBS. Pooled tissues were homogenized in lysis buffer $(50 \mathrm{~mm}$ Tris-Cl, pH 7.6, 120 mм NaCl, 0.5\% IGEPAL CA-630, 1 mM PMSF, $1 \times$ protease inhibitor mixture, 2 $\mathrm{mm} \mathrm{NaF}, 2 \mathrm{~mm} \mathrm{Na} \mathrm{VO}_{4}$, supplemented with $100 \mu \mathrm{M} \mathrm{CaCl}_{2}$, and $100 \mu \mathrm{M} \mathrm{MgCl}_{2}$ for $\mathrm{Ca}^{2+}$ containing buffer or $1 \mathrm{~mm}$ EDTA and $1 \mathrm{~mm}$ EGTA for $\mathrm{Ca}^{2+}$-free buffer), centrifuged at $13,000 \times \mathrm{g}, 4^{\circ} \mathrm{C}$ for $20 \mathrm{~min}$, and supernatants were collected. Supernatants were precleared by incubating with $50 \%$ protein G-sepharose beads and normal rabbit IgG for $30 \mathrm{~min}$. Precleared lysates were mixed with GFP primary antibody for $2 \mathrm{~h}$ (Rockland 011-0102), followed by protein G-sepharose beads for 45 min. Beads were collected by centrifugation at $3000 \times g$ for $1 \mathrm{~min}$, and washed eight times in lysis buffer without protease inhibitors. After final wash, $2 \times$ SDS buffer was added and the samples were boiled for $3 \mathrm{~min}$, centrifuged briefly, and supernatant were collected. Transfected HEK-293 cells were lysed in the same $\mathrm{Ca}^{2+}$-free buffer. Precipitated proteins and HEK-293 cell lysates were separated by SDSPAGE and transferred to PVDF membrane. A standard protocol using an ECL-plus kit (Pierce) detected the immunoblot signal. Antibodies used for Western blot were as follows: rabbit anti-GFP (Rockland, 1:1000), goat anti-CETN2 (1:500; Dr Wolfrum, Johannes Gutenberg University), KIF3A (1:500 SigmaAldrich), DYNC2H1, and DYNC1H1 (cytoplasmic dynein 1 heavy chain 1) (both 1:500; Dr Vallee, Columbia University).

Ependymal cilia beating assay. P13 male WT and Cetn2 mutant brain lateral ventricle walls were isolated in L15 medium (Mirzadeh et al., 2010). Red fluorescent microbeads (SigmaAldrich; $2 \mu \mathrm{m}$ diameter) were added and bead movement was recorded using a Nikon Ti-E Widefield CCD microscope. ImageJ software $(\mathrm{NIH})$ with manual tracking plugin was used to track individual particle movements and to calculate speed.

Statistical analysis. Data are presented as mean \pm SD where $n$ represents the number of mice or OSNs analyzed. Statistical comparisons (significant for $p<0.05$ ) were performed using two-way ANOVA with Bonferroni posttest for EOG results, and one-way ANOVA for all other experimental data.

\section{Results}

\section{Generation of Cetn $2 \mathrm{KO}$ mice}

The mouse X chromosome-located Cetn2 gene contains 5 exons. To generate a CETN2 KO mouse, we inserted a loxP site

of GFP-CETN2 signal in supranuclear region of an 0MP-positive OSN, probably an intermediate structure of de novo centriole formation pathway. Arrowhead marks a knob from another OSN that happened to be situated above the aforementioned OSN dendrite tip because of cut angle. Scale bars: $A, B, 2 \mu \mathrm{m}$; $\boldsymbol{C}, \boldsymbol{D}, 200 \mathrm{~nm} ; \boldsymbol{E}, 25 \mu \mathrm{m} ; \boldsymbol{F}, \boldsymbol{H}, 5 \mu \mathrm{m} ; \boldsymbol{G}, 20 \mu \mathrm{m}$. 
into intron 1 and a neomycin selection cassette flanked by two loxP sites into intron 3 to create the conditional allele (Fig. $1 A)$. By mating the floxed mouse with an EIIa-Cre driver, we generated an allele in which the neo cassette was eliminated and exons 2 and 3 were deleted in frame $\left(\operatorname{Cetn} 2^{\Delta \mathrm{Ex} 2,3}\right.$; Fig. $\left.1 A, B\right)$. Truncated Cetn2 mRNA (encompassing exons 1,4 , and 5) was detectable by RT/PCR but at very low levels (5-10\% of WT; Fig. $1 B$, red arrow). In the absence of Cetn2, Cetn1, and Cetn3, mRNA levels were normal with Cetn 4 being slightly upregulated by RT-PCR analysis (Fig. 1B). A CETN2 antibody (goat anti-full-length mouse CETN2) recognized the truncated GFP-CETN2 overexpressed in HEK-293 cells by immunoblot (Fig. 1C) and by immunostaining (Fig. 1D). The truncated protein was undetectable in Cetn2 mutant olfactory epithelia (OE) by immunostaining, whereas in WT OE endogenous CETN2 protein localized to the basal body/ centriole of OSN dendritic knob layer, (Fig. $1 E$, left), indicating that $\operatorname{Cetn} 2^{\Delta \mathrm{Ex} 2,3}$ is a null allele. In a GFP-Cetn 2 transgenic mouse (Higginbotham et al., 2004), GFP-CETN2 is similarly concentrated in basal bodies of OSNs, brain ependyma, and photoreceptors (also in photoreceptor connecting cilia; Fig. $1 E$, right).

Cetn 2 mutant mice display dysosmia and hydrocephalus

Cetn 2 mutants $\left(\right.$ Cetn $2^{-/-}$females or Cetn $2^{-/ Y}$ males) were born in a Mendelian ratio as expected for an $\mathrm{X}$-linked gene. Cetn 2 mutant appears normal at birth but its body size becomes smaller with age relative to WT or heterozygous littermates ( $\sim 30 \%$ lower than WT at weaning), consistent with a weight loss phenotype previously associated with olfactiondeficiency (Weiss et al., 2011). A behavioral test revealed that overnight-fasted Cetn2 mutants took over seven times longer to locate food than WT controls (350 vs $45 \mathrm{~s}$, data not shown), suggesting that they are dysosmic. We found that EOG amplitudes of Cetn2 $\mathrm{KO}$ mice were reduced by $48-69 \%$ with all tested odorants: $58 \%$ reduction for citral, $48 \%$ for S-butanol, 61\% for acetophenone, 69\% for cineole, and $67 \%$ for R-carvone (Fig. $1 F, H)$. Dose-dependent EOG recordings with amyl acetate showed amplitude reduction at every tested concentration (Fig. $1 G, I)$.

Cetn2 KO mice also presented with hydrocephalus of variable severity. Approximately 30\% of mutants develop a dome-shaped head reflecting a dilated brain ventricle (Fig. $1 J$ ) and die within 1.5 months. The other $70 \%$ have a normal skull shape but with brain ventricles dilated upon examination histologically (Fig. $1 K$; ages 1-12 months), indicating later onset of hydrocephaly after the sealing of cranial sutures. Dilation of lateral ventricle in mild
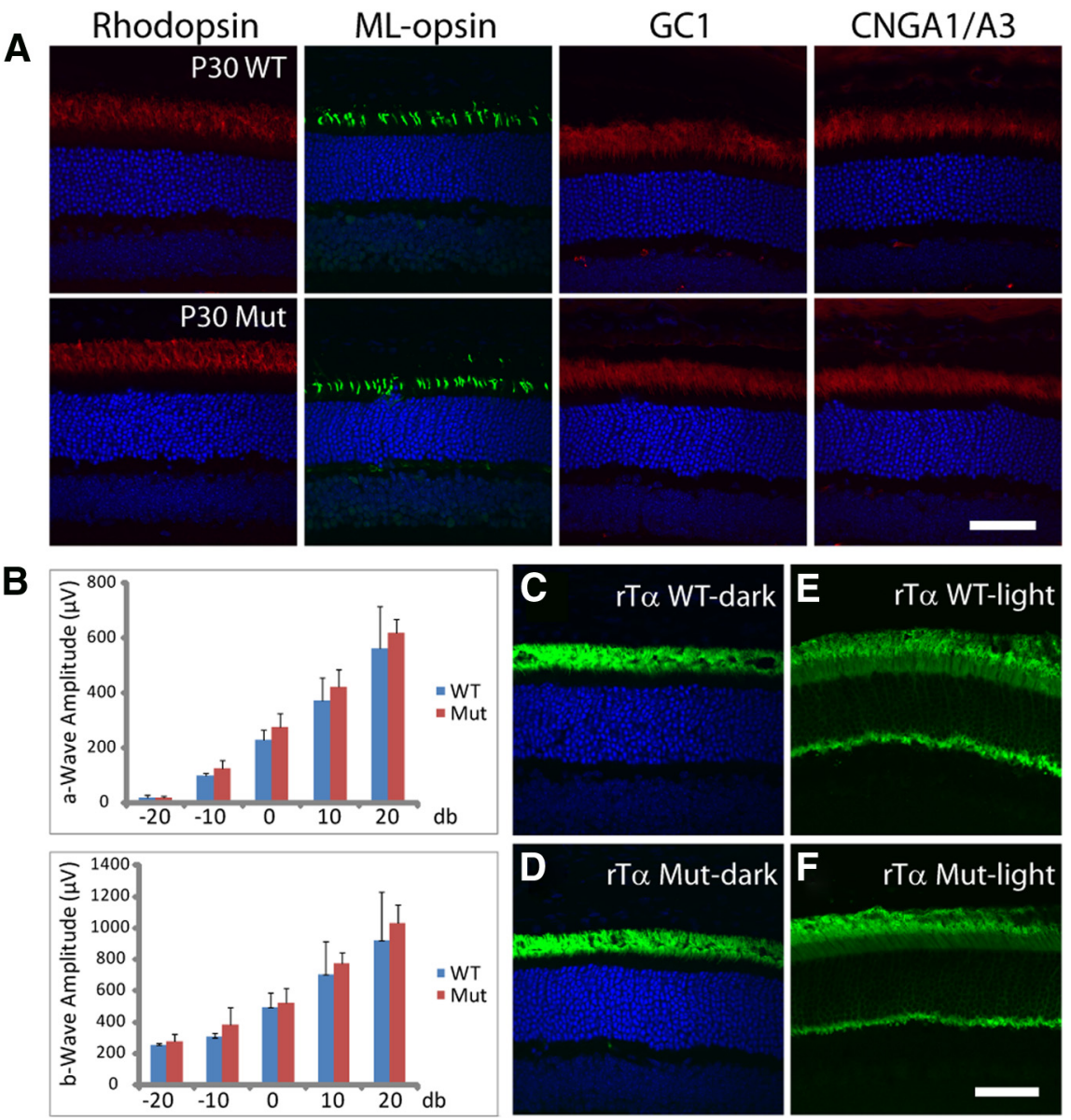

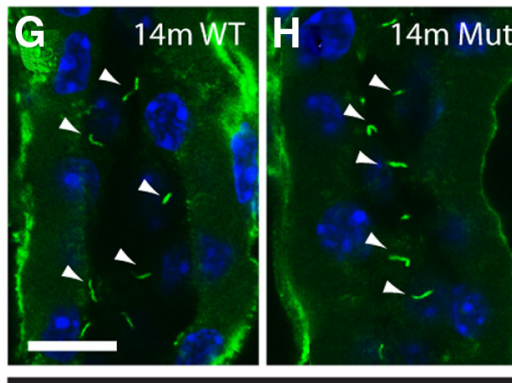

Renal tubule: Ac- $\alpha$-Tubulin
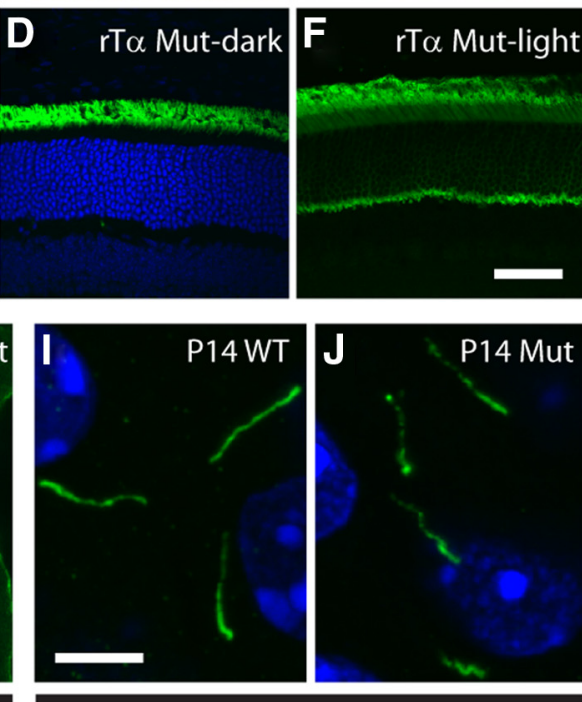

Brain Neurons: ACIII
Figure 5. Normal ciliary protein trafficking and translocation in Cetn2 mutant photoreceptors. A, Normal transport of photoreceptor outer segment proteins, including rhodopsin (red), ML-opsin (green), GC1 (red), and CNGA1/A3 (red) in retinas of 1-monthold WT (top) and Cetn2 mutant (lower) mice. B, Electroretinography of 1-month-old WT and Cetn2 mutant mice. No difference of scotopic ERG a-wave (top) or b-wave (lower) amplitude at multiple light intensities was observed. Data are shown as mean \pm SD for both a- and b-wave amplitudes ( $n=3$, one-way ANOVA, $p>0.7)$. $\mathbf{C}-\boldsymbol{F}$, Normal rod transducin localization in dark- $(\boldsymbol{C}, \boldsymbol{D})$ or light-adapted $(\boldsymbol{E}, \boldsymbol{F})$ WT $(\boldsymbol{C}, \boldsymbol{E})$ and Cetn2 mutant retinas $(\boldsymbol{D}, \boldsymbol{F}) . \boldsymbol{G}, \boldsymbol{H}, A \mathbf{C}-\alpha$-tubulin (green) immunostaining of renal tubule cilium (arrowheads) in 14-month-old WT and mutant kidney. $I, J, A C I I I$ labeling (green) of neuronal primary cilium of P14 WT and mutant brain neurons. Scale bars: $\boldsymbol{A}, \boldsymbol{C}-\boldsymbol{F}, 50 \mu \mathrm{m} ; \boldsymbol{G}, \boldsymbol{H}, 10 \mu \mathrm{m} ; \boldsymbol{I}, J, 5 \mu \mathrm{m}$.

hydrocephalus is more obvious than that of midbrain aqueduct or fourth ventricle (Fig. $1 K$ ).

We did not observe common primary cilium-related disease phenotypes, such as retinal degeneration (see below), polycystic kidney disease, polydactyly, or hedgehog signaling-related developmental defects in Cetn2 mutants.

Loss of olfactory cilia, but maintenance of ependymal cilia in Cetn 2 mutant mice

We investigated whether disruption of mutant olfactory or ependymal cilia occurs among $\operatorname{Cetn} 2^{-/ Y}$ males. Ac- $\alpha$-tubulin 


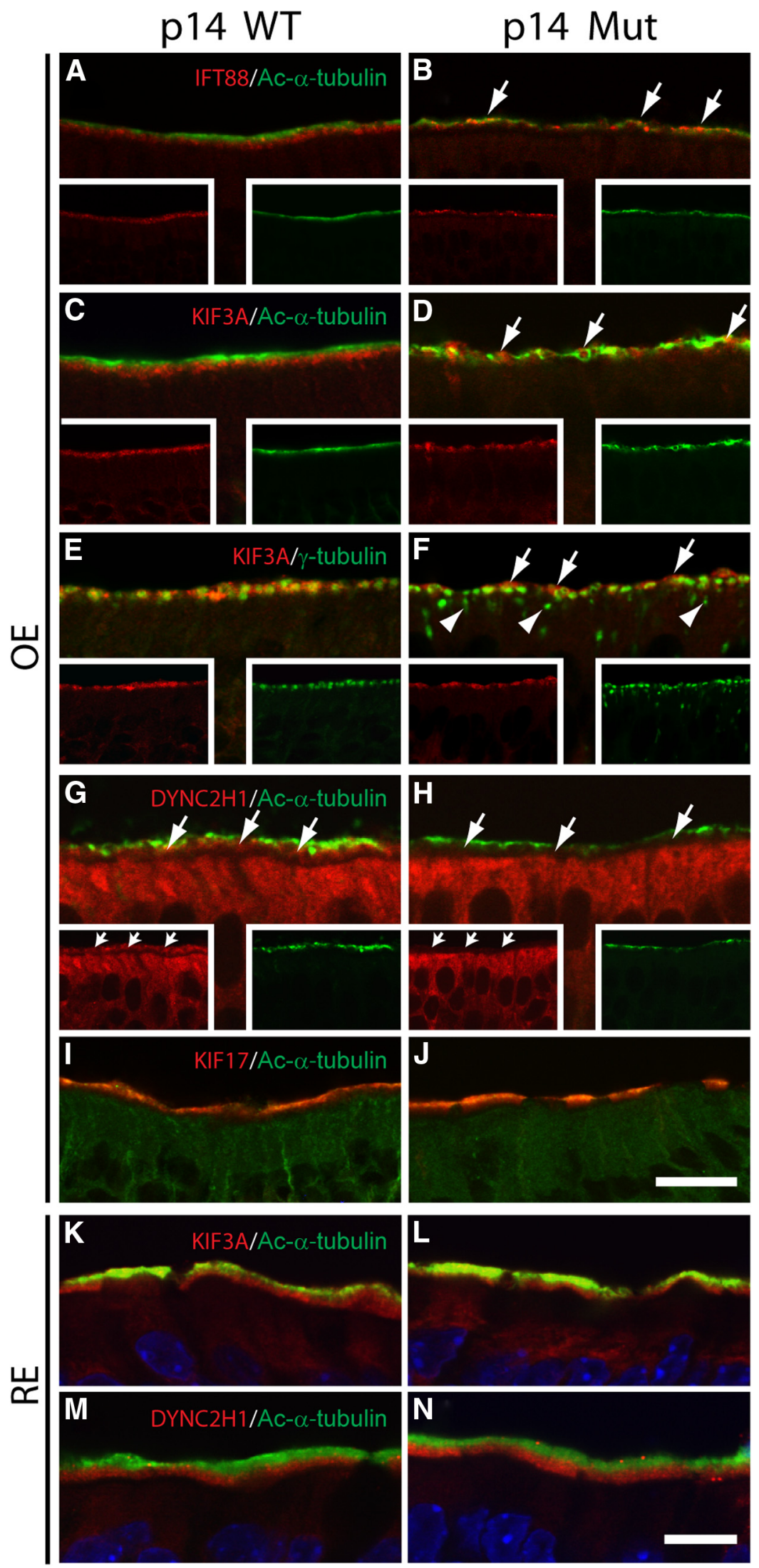

Figure 6. Mislocalized IFT components in P14 Cetn2 mutant OE. $\boldsymbol{A}, \boldsymbol{B}$, IFT88 (red) and Ac- $\alpha$-tubulin (green) colabeling of WT (A) and mutant ( $\boldsymbol{B})$ OE where IFT88 is localized in the ciliary layer (arrows) of the mutant. C, D, KIF3A (red) and Ac- $\alpha$-tubulin (green) colabeling of WT (C) and mutant (D) OE. KIF3A signal (arrows) appears intermingled with that of Ac- $\alpha$-tubulin (green) in the mutant ciliary layer. $\boldsymbol{E}, \boldsymbol{F}, \mathrm{KIF} 3 \mathrm{~A}$ (red) and $\boldsymbol{\gamma}$-tubulin (green) colabeling of WT $(\boldsymbol{E})$ and mutant $(\boldsymbol{F})$ OE. Note KIF3A localization (arrows) above the most superficial $\gamma$-tubulin signal in mutant. Arrowheads ( $\boldsymbol{F}$, mutant) indicate mislocalized basal bodies. (cilium marker) immunolabeling revealed substantial decrease of ciliary layer thickness with Ac- $\alpha$-tubulin-negative spots in mutant $\mathrm{OE}$ at $\mathrm{P} 14$ (Fig. $2 \mathrm{~A}, \mathrm{~B}$ ) and later (P21, P60, P180; data not shown). In scanning electron microscopy (SEM) of P16 OE tissues (turbinates II and II'), WT cilia formed a fine, dense meshwork (Fig. $2 C)$, whereas Cetn2 mutant cilia were reduced in density and appeared short and stubby with slightly enlarged tips (Fig. 2D, arrows), and several dendritic knobs (example at arrowhead) were enlarged. We labeled a subset of olfactory cilia with antiOR256-17 (olfactory receptor 15) antibody which has been used to track mouse olfactory ciliogenesis in an OSN subset (Schwarzenbacher et al., 2005). Compared with WT (Fig. 2E), numbers of Cetn2 mutant OR256-17-positive cilia were reduced dramatically in either coronal sections (Fig. $2 E, F$, arrows) or wholemounts, and remaining cilia were short and varicose (Fig. 2G-J, arrows). Quantification of OR256-17 immunostaining confirmed significant decrease of knob density ( 170.5 vs 93 , knobs per $0.1 \mathrm{~mm}^{2}$ ), cilium density ( 17 vs 6 , cilia number per knob), and average ciliary length $(22 \mu \mathrm{m}$ vs $7 \mu \mathrm{m}$; Fig. $2 K-M$ ).

Surprisingly, the density of lateral ventricle ependymal cilia in P21 Cetn2 mutants with early onset hydrocephalus is comparable with WT as determined by whole-mount Ac- $\alpha$-tubulin labeling (Fig. $2 N, O)$. However, the uniform anteriorpointing orientation of cilia appears to be disrupted among Cetn2 mutants (Fig. 2O, arrows). In SEM, P16 WT ependymal ciliary tufts show regular spacing and cilia within a tuft, or between tufts, show consistently uniform orientation (Fig. 2P), whereas mutant ependymal cilia within a tuft, or among adjacent tufts, frequently revealed cilia of variable orientation (Fig. $2 Q$, arrows). In addition, mutant respiratory cilia appear to be normal in density

$\boldsymbol{G}, \boldsymbol{H}, \mathrm{DYNC2H1}$ (red) and Ac- $\alpha$-tubulin (green) colabeling of WT (G) and mutant $(\boldsymbol{H})$ OE. DYNC2H1 labels WT knob layer, and is reduced dramatically in the mutant (arrows). Note that DYNC2 11 labeling of mutant dendrite and soma layer is unaltered. Insets in $\boldsymbol{A}-\boldsymbol{H}$ are single channel images of each labeling. I,J, KIF17 (red) and Ac- $\alpha$-tubulin (green) colabeling of WT (I) and mutant $(J) 0 \mathrm{E}$, showing KIF17 localization in cilia layer of both. $\boldsymbol{K}, \boldsymbol{L}, \mathrm{KIF} 3 \mathrm{~A}$ (red) and Ac- $\alpha$-tubulin (green) colabeling of P14 nasal respiratory epithelium. KIF3A appears concentrated at the ciliary bases of both WT $(\boldsymbol{K})$ and mutant (L). $\boldsymbol{M}, \boldsymbol{N}$, DYNC2H1 (red) and Ac- $\alpha$-tubulin (green) colabeling of P14 nasal respiratory epithelium, showing cytoplasmic dynein 2 concentration at ciliary bases of both WT $(\boldsymbol{M})$ and mutant $(\boldsymbol{N})$. Scale bars: $\boldsymbol{A}, \boldsymbol{B}, \boldsymbol{I}, \boldsymbol{J}, 30 \mu \mathrm{m} ; \boldsymbol{C}-\boldsymbol{H}, 20 \mu \mathrm{m} ; \boldsymbol{K}-\boldsymbol{N}, 50 \mu \mathrm{m}$ 
and axonemal ultrastructure (Fig. $2 R, S$, and insets), as well as determined by Ac$\alpha$-tubulin labeling, and with normal localizations of cytoplasmic dynein 2 and KIF3A at cilia bases (see Fig. $6 K-N$ ).

\section{Olfactory cilia trafficking failure occurs before cilia loss}

Documenting the onset of olfactory ciliary loss, we found that cilium density at early stages (P0, P5) is comparable between WT and mutant as determined by Ac- $\alpha$-tubulin (Fig. $3 A, B$ ) and OR256-17 (Fig. 3I-L) immunolabeling. Further, the pattern of three IFT components, IFT88, KIF3A (obligatory subunit of anterograde motor kinesin-II), and DYNC2H1 (IFT retrograde motor cytoplasmic dynein 2 heavy chain 1), is comparable between WT and mutant with IFT88 and DYNC2H1 concentrated at cilium layer and KIF3A concentrated at knob layer at these stages (Fig. 3C-H). Quantification of P5 wholemount OR256-17 signal revealed no difference of dendritic knob density (170 WT vs 175 mutant, knobs per $0.1 \mathrm{~mm}^{2}$ ), cilium density (19.2 WT vs 18.5 mutant, cilia number per knob), or average cilium length $(8.2 \mu \mathrm{m}$ WT vs $8.5 \mu \mathrm{m}$ mutant; Fig.

$3 M-O)$. Collectively, these measures indicate that olfactory ciliogenesis is initiated without CETN2. Interestingly, as early as P5, many turbinate I mutant OSNs showed dendrite and soma mislocalization of the olfactory signaling protein, ACIII (Fig. 3, compare $P, Q$, green). As the olfactory ciliary axoneme is present in these neurons, shown by $\alpha$-tubulin staining (Fig. 3Q, red), loss of CETN2 appears correlated with impaired membrane protein transport.

With OE development, the ciliary trafficking defect can be observed in all turbinates and septa. By P14 (and older), immunoreactivity for two major transmembrane signaling proteins, ACIII and CNGA2, showed massive mislocalization to OSN dendrites and cell bodies in mutants (Fig. $3 S, V$ ), in stark contrast to localization exclusively in the WT cilia layer(Fig. $3 R, U$ ). Localization of the olfactory G-protein, $\mathrm{G} \alpha_{\text {olf }}$ (a peripheral membrane-associated protein), appeared normal (Fig. $3 X, Y$ ).

\section{Transgenic GFP-Cetn2 rescues olfactory mistrafficking and other phenotypes}

Overexpression of GFP-CETN2 rescues the centriole assembly defect in CETN2-depleted mammalian cells (Yang et al., 2010). Correspondingly, we produced Cetn $2^{-/ Y}$;GFP-Cetn 2 mice by mating Cetn $2^{+/-}$female mice with GFP-Cetn 2 transgenic males (Higginbotham et al., 2004) in an attempt to "rescue" the OSN ciliary trafficking defect. As expected, ciliary localizations of ACIII, CNGA2, and $\mathrm{G} \alpha$ olf were normal in Cetn $2^{-/ Y}$; GFP-Cetn2 mice (Fig. $3 N, Q, T$ ). Further, the body weights of Cetn2 ${ }^{-/ Y}$; GFP-Cetn2 mice were indistinguishable from those of WT mice; hydrocephalus were not detected (among $>10$ mutants).

\section{Basal body mislocalization in postnatal Cetn 2 mutant OSN} Olfactory ciliogenesis starts with de novo basal body formations in the OSN soma followed by migration into dendritic knobs (Jenkins et al., 2009a). Ultrastructure reveals that dendritic knobs and basal bodies are located exclusively in the OE mucous layer of P14 WT mice (Fig. 4A), whereas in Cetn2 mutant littermates (Fig. $4 B$ ), many dendritic knobs and basal bodies were localized beneath the OE surface, indicating basal body apical migration/ docking defects. Short residual cilia with slightly swollen tips were observed in mutant OSNs (Fig. 4C,D, arrowheads), along with basal bodies having extra wall decoration (Fig. 4D, arrows). Since early olfactory ciliogenesis (before P5) appears to be normal in Cetn2 mutants, the mislocalized basal bodies may result from terminal migration and docking defects during postnatal OE maturation. Indeed, we found that GFP-CETN2 labeled centrioles are dispersed throughout OE in P7 GFP-CETN2 transgenic mice (Fig. 4E, arrows), and that at high-magnification GFPCETN2-postive dots could be seen at both OSN cell body and dendrite with some in clusters (Fig. $4 F$, arrows). As OE maturation is paralleled by the progressive increase of OSN numbers expressing olfactory marker protein (OMP, a mature OSN marker; Farbman and Margolis, 1980), we stained P7 sections with OMP antibody and found that a small fraction of basal bodies is located in OMP-positive OSN cell body and dendrite (Fig. 4G,H, arrows), although the majority are located in OMP-negative immature neurons (Fig. 4G, dashed arrows). These observations indicate that basal body terminal migration/docking failure could occur both in Cetn2 mutant immature and mature OSNs.

\section{Photoreceptor ciliary trafficking proceeds normally in Cetn 2 mutants}

All four centrin genes are expressed in murine photoreceptors (Giessl et al., 2004). Deletion of CETN2 did not affect the subcelluar localizations of photoreceptor outer segment proteins, including rod and cone visual pigments (rhodopsin, ML-opsin, and S-opsin), cGMP-gated channel subunits (CNGA1/A3), guanylate cyclase 1 (GC1), rod PDE6 and the structural proteins ROM1, and peripherin-2 (Fig. 5A, and data not shown). ERGs of 
1-month-old WT and Cetn2 mutant mice were indistinguishable (Fig. $5 B$ ). It has been proposed that photoreceptor centrins may regulate visual G-protein translocation (Trojan et al., 2008). However, we found that neither the light-driven translocation nor the dark-driven return of both rod transducin- $\alpha$ (Fig. $5 C-F$ ) and arrestin (data not shown) are impaired in Cetn 2 mutants.

Mutant renal tubule cilia appeared normal in morphology and density as judged by Ac- $\alpha$-tubulin immunostaining (Fig. $5 G, H)$. Another type of primary cilium, the ACIII-positive neuronal cilium of the brain, also appeared normal in density although ACIII distribution along the cilia was not as smooth as in WT (Fig. 5, compare $I, J$ ).

\section{Mislocalization of IFT components in Cetn2 mutant OSNs}

To test whether Cetn2 mutant OSN mislocalization of ACIII and CNGA2 involved altered IFT, we examined the distributions of IFT88, KIF3A, and DYNC2H1 in P14 animals. As reported (Miyoshi et al., 2009), IFT-88 and KIF3A concentrate at dendritic knob layer, beneath the Ac- $\alpha$-tubulin-positive ciliary layer (Fig. $6 A, C$ ), and overlap with the $\gamma$-tubulin signal (Fig. $6 E$ ). In mutants, IFT88- and KIF3A-positive layers are uneven and portions of each colocalize with Ac- $\alpha$-tubulin (Fig. 6B,D, arrows), suggesting that IFT88 and KIF3A are trapped in olfactory cilia. KIF3A and $\gamma$-tubulin double-labeling confirmed partial KIF3A localization above the superficial basal bodies (Fig. $6 F$ ). Interestingly, homodimeric KIF17, another member of the kinesin-II family required for sensory ciliogenesis in Caenorhabditis elegans and olfactory CNG channel cilium transport in mammalian cells (Snow et al., 2004; Jenkins et al., 2006), localized correctly in the olfactory cilium layer of Cetn2 mutant mice (Fig. 7 I, J). Trapping of IFT88 and KIF3A in the Cetn2 mutant ciliary layer suggests abnormal retrograde IFT, mediated by cytoplasmic dynein 2 (Collet et al., 1998; Pazour et al., 1999). Although DYNC2H1 soma layer labeling appeared unaltered, we found that DYNC2H1 ciliary base localization was dramatically decreased in Cetn2 mutant OE (Fig. 6G,H, insets, arrows). However, using GFP-CETN2 transgenic OE lysate and GFP antibody as a bait, we were unable to detect a direct interaction between CETN2 and DYNC2H1 or KIF3A (data not shown) in coimmunoprecipitation assays. Colabeling of KIF3 or DYNC2H1 with Ac- $\alpha$-tubulin in Cetn2 mutant respiratory epithelia, however, revealed normal basal body localization of these two motor proteins (Fig. $6 K-N$ ).

\section{Uncoordinated fluid flow generated by Cetn 2 mutant ependymal cilia}

The orientation of ependymal cilia (Fig. $2 L-O$ ) indicated an altered CSF flow phenotype in the Cetn 2 mutant. To test this possibility, we isolated and maintained P13 lateral ventricle walls in culture. Fluorescent latex microbeads (2 $\mu \mathrm{m}$ diameter) were added to the culture media and microbead movement was then recorded. Beads move from posterior to anterior when incubated with WT ependymal epithelia (Tissir et al., 2010; Fig. 7A; Movie 1), but with mutant ependymal epithelia, directional movement is disrupted, slowed (WT $45 \mu \mathrm{m} / \mathrm{s}$ vs mutant $8 \mu \mathrm{m} / \mathrm{s}$; Fig. $7 C$ ), and multidirectional (Fig. $7 B$; Movie 2). Impaired CSF directional flow coupled with ciliary misorientation of Cetn 2 mutant ependyma was interpreted to suggest improper development of planar polarity.

\section{Disrupted rotational planar polarity of ependymal cilia in Cetn2 mutants}

Because the basal foot direction determines ependymal cilia planar polarity and beating direction (Wallingford, 2010; Kishimoto

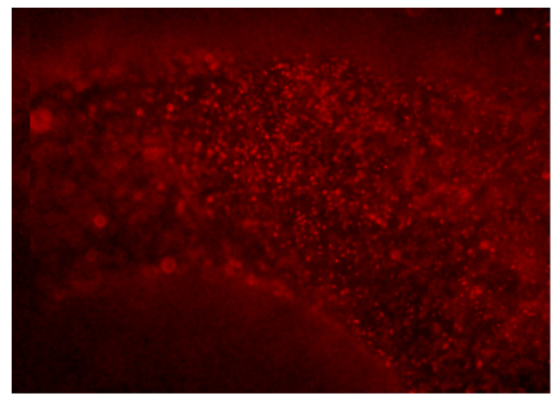

Movie 1. Fluorescent microbead movement along WT lateral ventricle surface. Beads move from posterior to anterior. Images were acquired at 25 frames/s and movie plays at 15 frames/s.

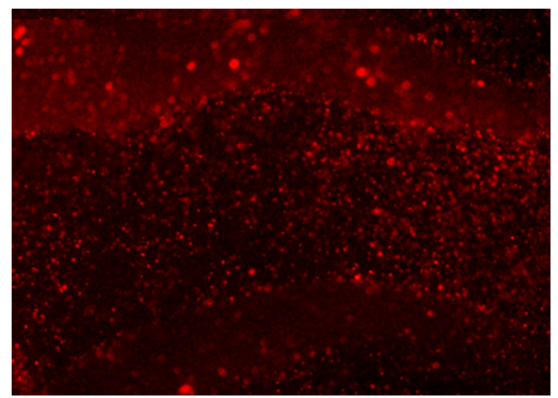

Movie 2. Movement of fluorescent microbeads along Cetn 2 mutant lateral ventricle surface. Beads move more slowly, and in random directions. Images were acquired at 25 frames/s and movie plays at 15 frames/s.

and Sawamoto, 2012), we examined the basal foot direction via ultrastructure of P13 mutant ependyma. Most WT basal feet point anteriorly but Cetn 2 mutant basal feet point randomly (Fig. $8 A, B$, arrows), thus accounting for the random direction of ciliary beating detected by bead movement. We frequently observed misaligned mutant ependymal cilia (Fig. 8C,D), with basal bodies showing two or more electron-dense basal feet (Fig. $8 B$, dashed arrows, $F$, arrows). As the ciliary $9+2$ axoneme organization and nine blade-like transitional fibers appeared normal in Cetn $2 \mathrm{mu}-$ tants (Fig. 8E,F), it seems unlikely that the impaired fluid flow phenotype resulted from ciliary structural deficiency.

\section{Discussion}

In vitro studies have yielded contradictory results regarding the function of vertebrate centrin in basal body replication (Middendorp et al., 2000; Salisbury et al., 2002; Kleylein-Sohn et al., 2007; Yang et al., 2010; Dantas et al., 2011). Morpholino-induced depletion of CETN2 in zebrafish causes cell-cycle delay due to chromosome misalignment-induced mitotic defects. Here, we found that Cetn2 mutant pups were born healthy and of normal size, suggesting that CETN2 is nonessential for mouse centrosome replication or mitotic cell division during embryonic stages. Rather, Cetn2 mutants showed selective ciliopathies, i.e., dysosmia and hydrocephalus of variable degree. In view of ubiquitous expression of CETN2 in mouse adult tissues (Hart et al., 2001), it is puzzling that germline deletion of CETN2 affects predominantly olfactory and ependymal cilia. As OSNs and retinal photoreceptor express all four centrin isoforms (Wolfrum and Salisbury, 1998; Fig. 1b), it appears unlikely that isoform functional redundancy accounts for the lack of retina phenotype in Cetn 2 mutant. Rather, Cetn 2 deficiency results in a tissue-specific phenotype reflecting the astonishing complexity and diversity of ciliary structure and function (Marshall, 2008a). 
In vitro RNAi knockdown of Cetn2 inhibits primary ciliogenesis in several mammalian cell lines (Graser et al., 2007; Mikule et al., 2007). Morpholino-induced depletion of zebrafish Cetn2 impairs embryonic ciliogenesis, resulting in multiple ciliopathies (including pronephric cyst formation, hydrocephalus, and olfactory organ ciliary defects; Delaval et al., 2011). Such observations led to the hypothesis that vertebrate centrin may be critical for ciliogenesis (Dantas et al., 2012). However, we show that mouse CETN2 is not required for ciliogenesis as the formations of both primary cilia (renal tubule epithelia and photoreceptors) and motile cilia (multiciliated respiratory and ependymal epithelia) occur normally in Cetn $2 \mathrm{mu}-$ tants. Because olfactory cilium density and morphology appear normal before P5, we conclude that the massive ciliary loss in P14 (and older) Cetn2 mutant OE (Figs. 2-4) results from compromised postnatal ( $>$ P5) basal-body apical migration/anchoring and ciliary maintenance. Why is CETN2 nonessential for the initiation of olfactory ciliogenesis, but required for later ciliary maintenance? In mouse OE, olfactory ciliogenes is initiated approximately at embryonic day (E) 12 (Cuschieri and Bannister, 1975), but ciliary targeting of olfactory signaling proteins occurs later (Menco, 1997; McEwen et al., 2008). For example, the cilia targeting of receptor OR 256-17 occurs around from E14 and OR37 enters the cilia from $\sim$ E15 (Schwarzenbacher et al., 2005). In rats, mRNA expression of ACIII was first detected $\sim \mathrm{E} 15$, whereas $\mathrm{G}_{\text {olf }}$ and CNGA2 channel are detectable starting from E16 and E19, respectively (Margalit and Lancet, 1993). Thus, initial olfactory ciliogenesis and axoneme assembly are independent of ciliary targeting of olfactory signaling proteins. How does CETN2 absence lead to olfactory loss? As sensory signaling pathways can remodel the architecture and regulate ciliary length (Mukhopadhyay et al., 2008; Ou et al., 2009; Besschetnova et al., 2010), we propose that signaling protein mistrafficking and altered IFT cause failure of olfactory ciliary maintenance. That ACIII mislocalization occurs before cilia loss in postnatal CETN2 mutant OSNs (Fig. 3) supports this explanation. Although no olfactory cilia loss occurs in mouse knock-out of either ACIII (Wong et al., 2000) or CNGA2 (Brunet et al., 1996), we suppose that combined membrane protein trafficking defects of AIII and CNGA2 (and very likely other membrane proteins) are cumulative in causing degeneration of olfactory cilia. Signaling and IFT are interrelated because signaling pathway-dependent ciliary remodeling requires IFT participation (Mukhopadhyay et al., 2008) and signaling messengers like cAMP and $\mathrm{Ca}^{2+}$ affect IFT in mammalian cells (Besschetnova et al., 2010; Collingridge et al., 2013).

OSN-specific mechanisms controlling the cilium entry of olfactory signaling proteins have been proposed (McEwen et al., 2008). Identified regulators include centrosomal protein CEP290/
NPHP6 which controls $\mathrm{G} \alpha$ olf and G $\gamma 13$ ciliary entry (McEwen et al., 2007), and PACS-1 (phosphofurin acidic cluster-sorting protein 1) regulating CNG channel trafficking (Jenkins et al., 2009b). Here we show that CETN2 is required for transport of ACIII and CNGA2, but not cytoplasmic $\mathrm{G} \alpha_{\text {olf }}$, echoing a previous conclusion that olfactory G-protein targeting is not coupled to ACIII or CNG channels (McEwen et al., 2007). The abnormal basal body recruitment of IFT components (IFT88, KIF3A, and DYNC2H1) suggests that compromised IFT may contribute toward the ciliary mistrafficking phenotype of Cetn2 mutants. Noticeably, ACIII could be targeted to the primary cilium of brain ACIII-positive neurons in Cetn2 mutants although the protein distribution appeared not smooth along the cilium (Fig. $5 J$ ), suggesting possible cell type-specific regulation of ACIII ciliary targeting. Curiously, Cetn2 mutants share significant phenotypic similarity with a mouse pericentrin (Pctn, a core PCM component) hypomorphic mutant $\left(P_{c t n}{ }^{\text {ocd/ocd }}\right)$ displaying OE-specific olfactory ciliary loss, ACIII mistrafficking, and defective basal body-anchoring of IFT components (Miyoshi et al., 2009), suggesting a possible interaction between PCTN and CETN2-mediated molecular pathways. 
Other mouse mutants, such as those of BBS and MKS proteins, also manifest disrupted olfactory ciliary transport (including ACIII and CNGA2) and lead to ciliary structural anomalies attributed to compromised IFT (Kulaga et al., 2004; Nishimura et al., 2004; Pluznick et al., 2011; Tadenev et al., 2011).

In mouse ependyma and other multiciliated tissue, establishment of ciliary polarity requires hydrodynamic force and its coordination with PCP proteins (Mitchell et al., 2007; Guirao et al., 2010). Deletion of core PCP protein, celsr 3 (Drosophila Flamingo ortholog), also results in ependymal ciliary polarity deficiency in mouse (Tissir et al., 2010). The mechanism by which flow information is transduced, and PCP signal instructs ciliary orientation is poorly understood. Elucidation of a mechanism is complicated further by the fact that some PCP proteins are located in both cilium and rootlet (Park et al., 2008; Guirao et al., 2010). Instructional cues for ciliary orientation ultimately impinge on the basal body. Here we show that a core basal body protein, CETN2, is required for PCP development of mouse ependymal cells. The role of CETN2 in specification of ependymal polarity is currently unknown. The rootlet-associated subapical actin network and basal foot-associated microtubule network of frog embryo epidermal cilia regulate establishment of global and local ciliary polarity, respectively (Werner et al., 2011). In mouse airway epithelia, initial PCP signals induce polarization of basal body-associated microtubules that secondarily orient the basal body (Vladar et al., 2012). We propose that CETN2, downstream of core PCP proteins, participates in PCP signal-mediated cytoskeletal rearrangement.

\section{References}

Avasthi P, Scheel JF, Ying G, Frederick JM, Baehr W, Wolfrum U (2013) Germline deletion of Cetn1 causes infertility in male mice. J Cell Sci 126:3204-3213. CrossRef Medline

Besschetnova TY, Kolpakova-Hart E, Guan Y, Zhou J, Olsen BR, Shah JV (2010) Identification of signaling pathways regulating primary cilium length and flow-mediated adaptation. Curr Biol 20:182-187. CrossRef Medline

Bornens M, Azimzadeh J (2007) Origin and evolution of the centrosome. Adv Exp Med Biol 607:119-129. CrossRef Medline

Brunet LJ, Gold GH, Ngai J (1996) General anosmia caused by a targeted disruption of the mouse olfactory cyclic nucleotide-gated cation channel. Neuron 17:681-693. CrossRef Medline

Collet J, Spike CA, Lundquist EA, Shaw JE, Herman RK (1998) Analysis of osm-6, a gene that affects sensory cilium structure and sensory neuron function in Caenorhabditis elegans. Genetics 148:187-200. Medline

Collingridge P, Brownlee C, Wheeler GL (2013) Compartmentalized calcium signaling in cilia regulates intraflagellar transport. Curr Biol 23: 2311-2318. CrossRef Medline

Cuschieri A, Bannister LH (1975) The development of the olfactory mucosa in the mouse: electron microscopy. J Anat 119:471-498. Medline

Dantas TJ, Wang Y, Lalor P, Dockery P, Morrison CG (2011) Defective nucleotide excision repair with normal centrosome structures and functions in the absence of all vertebrate centrins. J Cell Biol 193:307-318. CrossRef Medline

Dantas TJ, Daly OM, Morrison CG (2012) Such small hands: the roles of centrins/caltractins in the centriole and in genome maintenance. Cell Mol Life Sci 69:2979-2997. CrossRef Medline

Delaval B, Covassin L, Lawson ND, Doxsey S (2011) Centrin depletion causes cyst formation and other ciliopathy-related phenotypes in zebrafish. Cell Cycle 10:3964-3972. CrossRef Medline

Farbman AI, Margolis FL (1980) Olfactory marker protein during ontogeny: immunohistochemical localization. Dev Biol 74:205-215. CrossRef Medline

Friedberg F (2006) Centrin isoforms in mammals: relation to calmodulin. Mol Biol Rep 33:243-252. CrossRef Medline

Giessl A, Pulvermüller A, Trojan P, Park JH, Choe HW, Ernst OP, Hofmann KP, Wolfrum U (2004) Differential expression and interaction with the visual G-protein transducin of centrin isoforms in mammalian photoreceptor cells. J Biol Chem 279:51472-51481. CrossRef Medline

Graser S, Stierhof YD, Lavoie SB, Gassner OS, Lamla S, Le Clech M, Nigg EA (2007) Cep164, a novel centriole appendage protein required for primary cilium formation. J Cell Biol 179:321-330. CrossRef Medline

Guirao B, Meunier A, Mortaud S, Aguilar A, Corsi JM, Strehl L, Hirota Y, Desoeuvre A, Boutin C, Han YG, Mirzadeh Z, Cremer H, Montcouquiol M, Sawamoto K, Spassky N (2010) Coupling between hydrodynamic forces and planar cell polarity orients mammalian motile cilia. Nat Cell Biol 12:341-350. CrossRef Medline

Hart PE, Poynter GM, Whitehead CM, Orth JD, Glantz JN, Busby RC, Barrett SL, Salisbury JL (2001) Characterization of the X-linked murine centrin Cetn2 gene. Gene 264:205-213. CrossRef Medline

Hartman H, Fedorov A (2002) The origin of the eukaryotic cell: a genomic investigation. Proc Natl Acad Sci U S A 99:1420-1425. CrossRef Medline

Higginbotham H, Bielas S, Tanaka T, Gleeson JG (2004) Transgenic mouse line with green-fluorescent protein-labeled centrin 2 allows visualization of the centrosome in living cells. Transgenic Res 13:155-164. CrossRef Medline

Huang K, Diener DR, Mitchell A, Pazour GJ, Witman GB, Rosenbaum JL (2007) Function and dynamics of PKD2 in Chlamydomonas reinhardtii flagella. J Cell Biol 179:501-514. CrossRef Medline

Jenkins PM, Hurd TW, Zhang L, McEwen DP, Brown RL, Margolis B, Verhey KJ, Martens JR (2006) Ciliary targeting of olfactory CNG channels requires the CNGB1b subunit and the kinesin-2 motor protein, KIF17. Curr Biol 16:1211-1216. CrossRef Medline

Jenkins PM, McEwen DP, Martens JR (2009a) Olfactory cilia: linking sensory cilia function and human disease. Chem Senses 34:451-464. CrossRef Medline

Jenkins PM, Zhang L, Thomas G, Martens JR (2009b) PACS-1 mediates phosphorylation-dependent ciliary trafficking of the cyclic-nucleotidegated channel in olfactory sensory neurons. J Neurosci 29:10541-10551. CrossRef Medline

Jiang L, Zhang H, Dizhoor AM, Boye SE, Hauswirth WW, Frederick JM, Baehr W (2011) Long-term RNA interference gene therapy in a dominant retinitis pigmentosa mouse model. Proc Natl Acad Sci U S A 108: 18476-18481. CrossRef Medline

Kishimoto N, Sawamoto K (2012) Planar polarity of ependymal cilia. Differentiation 83:S86-90. CrossRef Medline

Kleylein-Sohn J, Westendorf J, Le Clech M, Habedanck R, Stierhof YD, Nigg EA (2007) Plk4-induced centriole biogenesis in human cells. Dev Cell 13:190-202. CrossRef Medline

Kozminski KG, Beech PL, Rosenbaum JL (1995) The Chlamydomonas kinesin-like protein FLA10 is involved in motility associated with the flagellar membrane. J Cell Biol 131:1517-1527. CrossRef Medline

Kulaga HM, Leitch CC, Eichers ER, Badano JL, Lesemann A, Hoskins BE, Lupski JR, Beales PL, Reed RR, Katsanis N (2004) Loss of BBS proteins causes anosmia in humans and defects in olfactory cilia structure and function in the mouse. Nat Genet 36:994-998. CrossRef Medline

Kunimoto K, Yamazaki Y, Nishida T, Shinohara K, Ishikawa H, Hasegawa T, Okanoue T, Hamada H, Noda T, Tamura A, Tsukita S, Tsukita S (2012) Coordinated ciliary beating requires Odf2-mediated polarization of basal bodies via basal feet. Cell 148:189-200. CrossRef Medline

Lechtreck KF, Delmotte P, Robinson ML, Sanderson MJ, Witman GB (2008) Mutations in Hydin impair ciliary motility in mice. J Cell Biol 180:633643. CrossRef Medline

Margalit T, Lancet D (1993) Expression of olfactory receptor and transduction genes during rat development. Brain Res Dev Brain Res 73:7-16. CrossRef Medline

Marshall WF (2008a) The cell biological basis of ciliary disease. J Cell Biol 180:17-21. CrossRef Medline

Marshall WF (2008b) Basal bodies platforms for building cilia. Curr Top Dev Biol 85:1-22. CrossRef Medline

Marshall WF, Qin H, Rodrigo Brenni M, Rosenbaum JL (2005) Flagellar length control system: testing a simple model based on intraflagellar transport and turnover. Mol Biol Cell 16:270-278. CrossRef Medline

McEwen DP, Koenekoop RK, Khanna H, Jenkins PM, Lopez I, Swaroop A, Martens JR (2007) Hypomorphic CEP290/NPHP6 mutations result in anosmia caused by the selective loss of G-proteins in cilia of olfactory sensory neurons. Proc Natl Acad Sci U S A 104:15917-15922. CrossRef Medline

McEwen DP, Jenkins PM, Martens JR (2008) Olfactory cilia: our direct neu- 
ronal connection to the external world. Curr Top Dev Biol 85:333-370. CrossRef Medline

McIntyre JC, Davis EE, Joiner A, Williams CL, Tsai IC, Jenkins PM, McEwen DP, Zhang L, Escobado J, Thomas S, Szymanska K, Johnson CA, Beales PL, Green ED, Mullikin JC; NISC Comparative Sequencing Program, Sabo A, Muzny DM, Gibbs RA, Attié-Bitach T, Yoder BK, et al (2012) Gene therapy rescues cilia defects and restores olfactory function in a mammalian ciliopathy model. Nat Med 18:1423-1428. CrossRef Medline

Menco BP (1997) Ultrastructural aspects of olfactory signaling. Chem Senses 22:295-311. CrossRef Medline

Middendorp S, Küntziger T, Abraham Y, Holmes S, Bordes N, Paintrand M, Paoletti A, Bornens M (2000) A role for centrin 3 in centrosome reproduction. J Cell Biol 148:405-416. CrossRef Medline

Mikule K, Delaval B, Kaldis P, Jurcyzk A, Hergert P, Doxsey S (2007) Loss of centrosome integrity induces p38-p53-p21-dependent $\mathrm{G}_{1}-\mathrm{S}$ arrest. Nat Cell Biol 9:160-170. CrossRef Medline

Mirzadeh Z, Han YG, Soriano-Navarro M, García-Verdugo JM, AlvarezBuylla A (2010) Cilia organize ependymal planar polarity. J Neurosci 30:2600-2610. CrossRef Medline

Mitchell B, Jacobs R, Li J, Chien S, Kintner C (2007) A positive feedback mechanism governs the polarity and motion of motile cilia. Nature 447: 97-101. CrossRef Medline

Miyoshi K, Kasahara K, Miyazaki I, Shimizu S, Taniguchi M, Matsuzaki S, Tohyama M, Asanuma M (2009) Pericentrin, a centrosomal protein related to microcephalic primordial dwarfism, is required for olfactory cilia assembly in mice. FASEB J 23:3289-3297. CrossRef Medline

Mukhopadhyay S, Lu Y, Shaham S, Sengupta P (2008) Sensory signalingdependent remodeling of olfactory cilia architecture in C. elegans. Dev Cell 14:762-774. CrossRef Medline

Mukhopadhyay S, Wen X, Chih B, Nelson CD, Lane WS, Scales SJ, Jackson PK (2010) TULP3 bridges the IFT-A complex and membrane phosphoinositides to promote trafficking of G-protein-coupled receptors into primary cilia. Genes Dev 24:2180-2193. CrossRef Medline

Nishimura DY, Fath M, Mullins RF, Searby C, Andrews M, Davis R, Andorf JL, Mykytyn K, Swiderski RE, Yang B, Carmi R, Stone EM, Sheffield VC (2004) Bbs2-null mice have neurosensory deficits, a defect in social dominance, and retinopathy associated with mislocalization of rhodopsin. Proc Natl Acad Sci U S A 101:16588-16593. CrossRef Medline

Ocbina PJ, Eggenschwiler JT, Moskowitz I, Anderson KV (2011) Complex interactions between genes controlling trafficking in primary cilia. Nat Genet 43:547-553. CrossRef Medline

Ou Y, Ruan Y, Cheng M, Moser JJ, Rattner JB, van der Hoorn FA (2009) Adenylate cyclase regulates elongation of mammalian primary cilia. Exp Cell Res 315:2802-2817. CrossRef Medline

Park TJ, Mitchell BJ, Abitua PB, Kintner C, Wallingford JB (2008) Dishevelled controls apical docking and planar polarization of basal bodies in ciliated epithelial cells. Nat Genet 40:871-879. CrossRef Medline

Pazour GJ, Dickert BL, Witman GB (1999) The DHC1b (DHC2) isoform of cytoplasmic dynein is required for flagellar assembly. J Cell Biol 144:473481. CrossRef Medline

Pluznick JL, Rodriguez-Gil DJ, Hull M, Mistry K, Gattone V, Johnson CA, Weatherbee S, Greer CA, Caplan MJ (2011) Renal cystic disease proteins play critical roles in the organization of the olfactory epithelium. PLoS One 6:e19694. CrossRef Medline

Qin H, Burnette DT, Bae YK, Forscher P, Barr MM, Rosenbaum JL (2005) Intraflagellar transport is required for the vectorial movement of TRPV channels in the ciliary membrane. Curr Biol 15:1695-1699. CrossRef Medline

Salisbury JL (2007) A mechanistic view on the evolutionary origin for centrin-based control of centriole duplication. J Cell Physiol 213:420428. CrossRef Medline
Salisbury JL, Suino KM, Busby R, Springett M (2002) Centrin-2 is required for centriole duplication in mammalian cells. Curr Biol 12:1287-1292. CrossRef Medline

Schwarzenbacher K, Fleischer J, Breer H (2005) Formation and maturation of olfactory cilia monitored by odorant receptor-specific antibodies. Histochem Cell Biol 123:419-428. CrossRef Medline

Snow JJ, Ou G, Gunnarson AL, Walker MR, Zhou HM, Brust-Mascher I, Scholey JM (2004) Two anterograde intraflagellar transport motors cooperate to build sensory cilia on C. elegans neurons. Nat Cell Biol 6:11091113. CrossRef Medline

Tadenev AL, Kulaga HM, May-Simera HL, Kelley MW, Katsanis N, Reed RR (2011) Loss of Bardet-Biedl syndrome protein-8 (BBS8) perturbs olfactory function, protein localization, and axon targeting. Proc Natl Acad Sci U S A 108:10320-10325. CrossRef Medline

Tissir F, Qu Y, Montcouquiol M, Zhou L, Komatsu K, Shi D, Fujimori T, Labeau J, Tyteca D, Courtoy P, Poumay Y, Uemura T, Goffinet AM (2010) Lack of cadherins Celsr2 and Celsr3 impairs ependymal ciliogenesis, leading to fatal hydrocephalus. Nat Neurosci 13:700-707. CrossRef Medline

Trojan P, Krauss N, Choe HW, Giessl A, Pulvermüller A, Wolfrum U (2008) Centrins in retinal photoreceptor cells: regulators in the connecting cilium. Prog Retin Eye Res 27:237-259. CrossRef Medline

Vladar EK, Bayly RD, Sangoram AM, Scott MP, Axelrod JD (2012) Microtubules enable the planar cell polarity of airway cilia. Curr Biol 22:22032212. CrossRef Medline

Wallingford JB (2010) Planar cell polarity signaling, cilia and polarized ciliary beating. Curr Opin Cell Biol 22:597-604. CrossRef Medline

Wei Q, Xu Q, Zhang Y, Li Y, Zhang Q, Hu Z, Harris PC, Torres VE, Ling K, Hu J (2013) Transition fibre protein FBF1 is required for the ciliary entry of assembled intraflagellar transport complexes. Nat Commun 4:2750. CrossRef Medline

Weiss J, Pyrski M, Jacobi E, Bufe B, Willnecker V, Schick B, Zizzari P, Gossage SJ, Greer CA, Leinders-Zufall T, Woods CG, Wood JN, Zufall F (2011) Loss-of-function mutations in sodium channel Nav1.7 cause anosmia. Nature 472:186-190. CrossRef Medline

Werner ME, Hwang P, Huisman F, Taborek P, Yu CC, Mitchell BJ (2011) Actin and microtubules drive differential aspects of planar cell polarity in multiciliated cells. J Cell Biol 195:19-26. CrossRef Medline

Williams CL, Li C, Kida K, Inglis PN, Mohan S, Semenec L, Bialas NJ, Stupay RM, Chen N, Blacque OE, Yoder BK, Leroux MR (2011) MKS and NPHP modules cooperate to establish basal body/transition zone membrane associations and ciliary gate function during ciliogenesis. J Cell Biol 192:1023-1041. CrossRef Medline

Wilson GR, Wang HX, Egan GF, Robinson PJ, Delatycki MB, O’Bryan MK, Lockhart PJ (2010) Deletion of the Parkin coregulated gene causes defects in ependymal ciliary motility and hydrocephalus in the quakingviable mutant mouse. Hum Mol Genet 19:1593-1602. CrossRef Medline

Wolfrum U, Salisbury JL (1998) Expression of centrin isoforms in the mammalian retina. Exp Cell Res 242:10-17. CrossRef Medline

Wong ST, Trinh K, Hacker B, Chan GC, Lowe G, Gaggar A, Xia Z, Gold GH, Storm DR (2000) Disruption of the type III adenylyl cyclase gene leads to peripheral and behavioral anosmia in transgenic mice. Neuron 27:487497. CrossRef Medline

Yang CH, Kasbek C, Majumder S, Yusof AM, Fisk HA (2010) Mps1 phosphorylation sites regulate the function of centrin 2 in centriole assembly. Mol Biol Cell 21:4361-4372. CrossRef Medline

Ye X, Zeng H, Ning G, Reiter JF, Liu A (2014) C2cd3 is critical for centriolar distal appendage assembly and ciliary vesicle docking in mammals. Proc Natl Acad Sci U S A 111:2164-2169. CrossRef Medline 